\title{
The relationship of teachers' perceptions of high school principal's monitoring student progress and student achievement in southeastern Ohio
}

T. C. Chappelear

West Virginia University

Follow this and additional works at: https://researchrepository.wvu.edu/etd

\section{Recommended Citation}

Chappelear, T. C., "The relationship of teachers' perceptions of high school principal's monitoring student progress and student achievement in southeastern Ohio" (2011). Graduate Theses, Dissertations, and Problem Reports. 3097.

https://researchrepository.wvu.edu/etd/3097

This Dissertation is protected by copyright and/or related rights. It has been brought to you by the The Research Repository @ WVU with permission from the rights-holder(s). You are free to use this Dissertation in any way that is permitted by the copyright and related rights legislation that applies to your use. For other uses you must obtain permission from the rights-holder(s) directly, unless additional rights are indicated by a Creative Commons license in the record and/ or on the work itself. This Dissertation has been accepted for inclusion in WVU Graduate Theses, Dissertations, and Problem Reports collection by an authorized administrator of The Research Repository @ WVU.

For more information, please contact researchrepository@mail.wvu.edu. 
The relationship of teachers' perceptions of high school principal's monitoring student progress and student achievement in southeastern Ohio.

\section{T.C. Chappelear}

Dissertation submitted to the College of Human Resources and Education at West Virginia University

in partial fulfillment of the requirements

for the degree of

\section{Doctor of Education}

in

Educational Leadership Studies

Ted Price, Ph.D., Chair

Paul Chapman, Ph.D.

Sebastian Diaz, Ph.D.

Terence C. Ahern, Ph.D.

Lorrinda Saxby, Ed.D.

Department of Educational Leadership Studies

Morgantown, West Virginia

2011

Keywords: Principal Leadership, Instructional Leadership, Principal Instructional Management Rating Scale, Monitoring Student Progress

Copyright 2011 T.C. Chappelear 


\section{ABSTRACT \\ The relationship of teachers' perceptions of high school principal's monitoring student progress and student achievement in southeastern Ohio.}

\section{T.C. Chappelear}

Principals in school buildings across this nation and perhaps throughout the world are under immense pressure to improve outcomes for all students. Recent literature suggests this accountability may be warranted, at least in part, as there is overwhelming evidence that building principals can positively impact student achievement through their behavior as effective instructional leaders. Much of the evidence for this emanates from the elementary school level. The problem is that little research exists at the high school level to examine the relationship between building principals monitoring student progress and student achievement.

This baseline study examined the relationship between teachers' perceptions of principal behavior in monitoring student progress and student achievement. The Principal Instructional Management Rating Scale was used to collect teacher perceptions of principal behavior in the subscale of Monitor Student Progress. Proxies of student achievement consisted of each high school's Performance Index. Analysis of variance (ANOVA) was used to determine that a statistically significant relationship existed between teachers' perceptions of principals' monitoring student progress and student achievement. This research could guide the practices of several groups of stakeholders from the local level through the state level. 


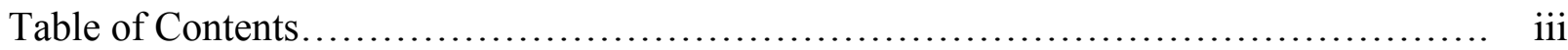

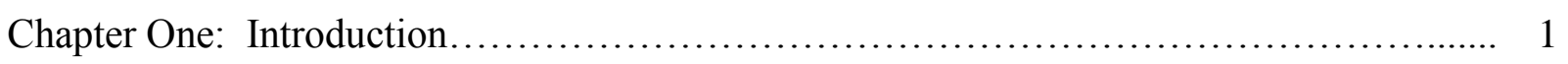

Statement of the Problem................................................. 2

Purpose of the Study.................................................... 4

Research Questions...................................................... 5

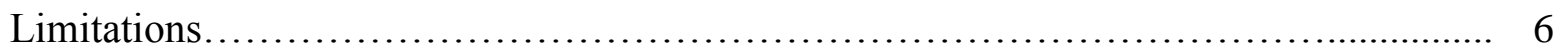

Significance............................................................ 6

Definition of Terms....................................................... 9

Summary and Organization of the Study.................................. 10

Chapter Two: Review of Literature........................................ 12

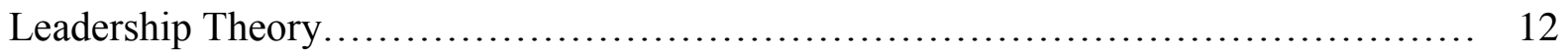

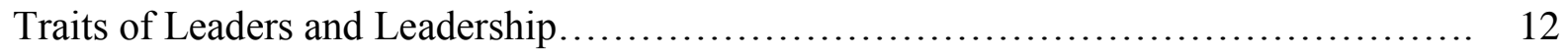

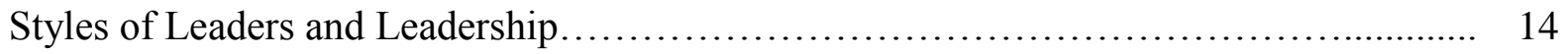

Behavioral Studies of Leaders and Leadership................................. 16

Situational and Contingency Studies of Leaders and Leadership................... 17

Hersey and Blanchard's Situational Leadership................................ 17

Vroom and Yetton's Normative Model......................................... 18

House's Path-Goal Theory of Leadership $\ldots \ldots \ldots \ldots \ldots \ldots \ldots \ldots \ldots \ldots \ldots \ldots \ldots \ldots \ldots . \ldots \ldots$

Fiedler's Contingency Model of Leader Effectiveness............................. 19

Transactional Leadership.................................................. 20

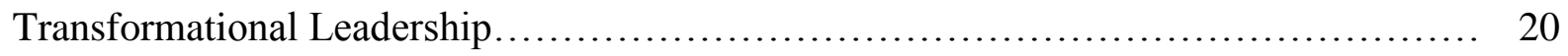

Principal Leadership $\ldots \ldots \ldots \ldots \ldots \ldots \ldots \ldots \ldots \ldots \ldots \ldots \ldots \ldots \ldots \ldots \ldots \ldots \ldots \ldots \ldots \ldots \ldots \ldots . . \quad 20$

Effective Schools Research............................................... 21 
Principal Effects of Student Achievement.................................... 22

Syntheses and Meta-Analytic Research.................................... 25

Syntheses.......................................................... 25

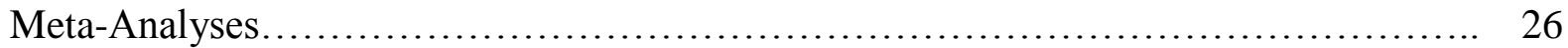

Instructional Leadership Versus Transformational Leadership....................... 33

Principals Monitoring Student Progress...................................... 34

Meet Individually with Teachers to Discuss Student Progress......................... 34

Discuss Academic Performance Results with Faculty to Identify Curricular Strengths

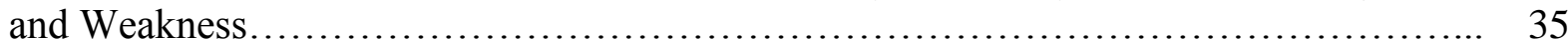

Use Tests and Other Performance Measures to Assess Progress Toward School

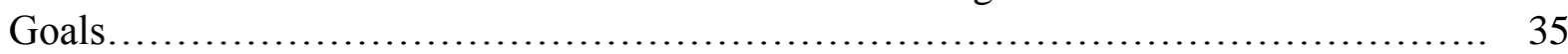

Inform Teachers of the School's Performance Results in Written Form............... 36

Inform Students of the School's Academic Performance............................... 36

Data Utilization...................................................... 37

Importance of Data Utilization by the School Principal............................ 37

The Data Used to Drive Instruction....................................... 38

How Principals Use Data........................................................ 39

Barriers and Facilitators of Data Use by School Principals........................ 41

Teacher Perceptions of Standardized Testing ................................. 42

Chapter Three: Methods.................................................... 44

Restatement of the Problem................................................ 44

Significance of the Problem................................................ 45

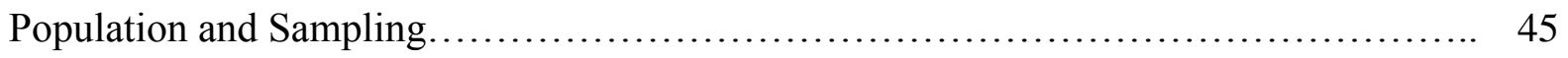

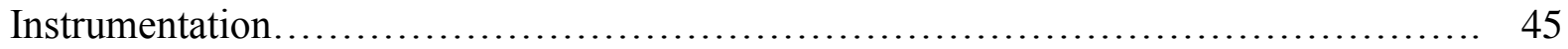

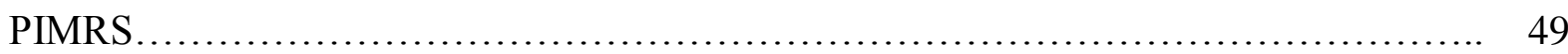


Perceptions of Standardized Testing Survey Items............................ 51

OGT - Reading and Math.................................................... 52

Performance Index........................................................ 56

Data Collection........................................................... 56

Data Analysis......................................................... 60

Guarantee of Anonymity and Confidentiality................................. 61

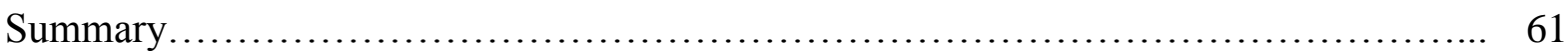

Chapter Four: Results.................................................. 63

Description of Sample.................................................. 66

Summary of Monitoring Student Progress Results ............................ 69

Meet individually with teachers to discuss student progress $\ldots \ldots \ldots \ldots \ldots \ldots \ldots \ldots \ldots \ldots . \ldots \ldots$

Discuss academic performance results with faculty to identify curricular strengths....... 71

Use tests and other performance measures to assess progress toward school goal........ 71

Inform teachers of the school's performance results in written form.................. 72

Inform students of the school's academic progress ............................. 73

Hypothesis and null hypothesis............................................. 74

Summary of teacher perceptions of standardized testing $\ldots \ldots \ldots \ldots \ldots \ldots \ldots \ldots \ldots \ldots \ldots \ldots$

Teacher perceptions of standardized testing.................................... 75

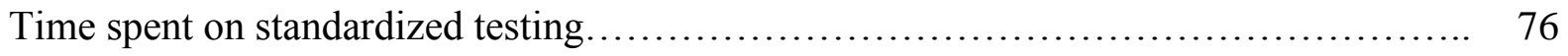

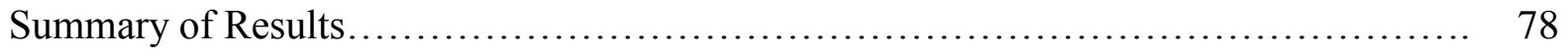

Chapter Five: Discussion and Implications....................................... 79

Limitations........................................................... 82

Discussion.............................................................. 82

Monitor Student Progress Subscale of the PIMRS $\ldots \ldots \ldots \ldots \ldots \ldots \ldots \ldots \ldots \ldots \ldots \ldots \ldots . . . \ldots 3$ 
Meet individually with teachers to discuss student progress........................ 83

Discuss academic performance results with faculty to identify curricular strengths........ 84

Use tests and other performance measures to assess progress toward school goal........ 86

Inform teachers of the school's performance results in written form................. 87

Inform students of the school's academic progress.............................. 89

Teachers' Perceptions of Standardized Testing................................ 90

Teachers' Perceptions of the Use of Student Achievement Data....................... 91

Implications......................................................... 92

Additional research......................................................... 96

Recommendations......................................................... 96

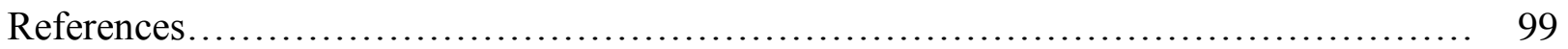

Appendix A Region 12 High Schools.......................................... 107

Appendix B Letter of Permission to use the PIMRS............................ 108

Appendix C Superintendent Letter of Solicitation................................. 109

Appendix D Formal Letter of Consent....................................... 110

Appendix E Principal's Letter of Participation................................. 111

Appendix F Teacher Letter of Participation.................................. 112

Appendix G PIMRS Teacher Form A......................................... 113 


\section{List of Tables}

Table 2.1

Fiedler's Model of Leader Effectiveness.

19

Table 2.2

The 21 Responsibilities of the School Leader.

Table 2.3 Leadership Dimensions from 11 Studies of Effects of Leadership on Student Outcomes......................... 32

Table 3.1

Respondents by Category.

Table 3.2

High Schools by Achievement Group 48

Table 3.3

Math Content Advisory Committee for 6 July 2005 . 54

Table 3.4

Cronbach Alpha Statistics for the Spring 2006 OGT... 55

Table 3.5

Score Ranges for the 2010 Ohio Graduation Test.

56

Table 3.6

Example Performance Index Calculation. ... 57

Table 4.1

High Schools by Achievement Group.

67

Table 4.2

Respondents by Category. 68

Table 4.3

Teaching Experience with Current Principal.. 68

Table 4.4 Teaching Experience. 69

Table 4.5

PIMRS Teacher Response Means 70

Table 4.6 ANOVA Item 1 from PIMRS. 70

Table 4.7 ANOVA Item 2 from PIMRS. 71

Table 4.8

ANOVA Item 3 from PIMRS 72

Table 4.9

ANOVA Item 4 from PIMRS 73

Table 4.10 ANOVA Item 5 from PIMRS 73

Table 4.11

Significant Differences Comparison. 74

Table 4.12

Teacher Perceptions of Standardized Testing. 76

Table 4.13

Teacher Perceptions of Time Spent on Standardized Testing..... 77

Table 5.1 Meet Individually with Teachers to Discuss Student Progress.... 
Table $5.2 \quad$ Discuss Performance Results with Faculty................... 86

Table $5.3 \quad$ Use Tests to Assess Progress.............................. 87

Table 5.4 Inform Teachers of the School's Performance Results.......... 88

Table 5.5 Inform Students of the School's Academic Progress............ 89

Table 5.6 Means of Teachers' Perceptions of Standardized Testing....... 90

Table 5.7 Teachers' Perceptions of Achievement Data Use............... 91 


\section{Chapter One: Introduction}

There has never been a lack of criticism or concern over the state of America's system of public education. The report, A Nation at Risk (1983), leveled criticism at just about every aspect of public schooling from content to teaching. In recent years, Rising Above the Gathering Storm: Energizing and Employing America for a Brighter Economic Future (2005) which focused on the ability of Americans to compete for employment in a global economy sounded the warning signals that our schools are not up to the task of turning out citizens who can compete in such an environment. Most recently, Rising Above the Gathering Storm, Revisited (2010) revisits the original report five years later and updates the earlier findings. The following is a small sample of evidence that the gathering storm is rapidly approaching Category 5:

- The United States ranks 20th in high school completion rate among industrialized nations and 16th in college completion rate.

- Sixty-Eight percent of U.S. state prison inmates are high school drop-outs or otherwise did not qualify for a diploma.

- According to the ACT College Readiness report, 78 percent of high school graduates did not meet the readiness benchmark levels for one or more entry-level college course in mathematics, science, reading and/or English.

The good news is that we know more about what makes a school effective than any previous time in history. High school principals can promote college readiness for students in their schools by monitoring student progress directly and/or indirectly. Interventions are a key factor in ensuring that students will have the core skills they need to be college and career ready. In order to use interventions to improve outcomes for students with academic deficiencies, there must be a process in place to identify them initially and then to monitor their progress as teachers work with them (ACT, 2008). 
Research supports the notion that principal leadership is important. Recent metaanalyses of the relationship between school leadership and student achievement suggest the impact of school leadership is second only to the effect of the classroom teacher on student outcomes (Hattie, 2009). One common theme that emerges from these studies is the importance of using data to monitor student progress. This is especially apparent at the elementary school level as many of these studies examine elementary schools rather than high schools (Cotton, 2003; Hattie, 2009; Marzano, Waters \& McNulty, 2005; Robinson, 2007). This study will add to the literature by examining the relationship between high school principals monitoring student progress and student achievement in southeastern Ohio. Additionally, this study will descriptively examine the relationship between high school teachers' perceptions of standardized testing

This chapter is presented in seven sections beginning with a discussion of what factors and forces are pushing school principals to engage in the use of data to monitor student progress. The second section clarifies the purpose of the study as examining the relationship between teachers' perceptions of principals' monitoring student progress and student achievement at the high school level. Third is a presentation of the research questions addressed in this study followed by a list of limitations of this study. The fifth section describes the professional significance of this study while the next section provides the definitions of terms important to the topic. Finally, Chapter One ends with a brief summary and an explanation of the organization for the remaining chapters.

\section{Statement of the Problem}

Principals in school buildings across this nation and perhaps throughout the world are under immense pressure to improve outcomes for all students (Witziers, Bosker \& Kruger, 2003; Robinson, 2007; Hallinger, 2008; Marzano, Waters \& McNulty, 2005). No Child Left Behind (2002) holds schools accountable to narrow the achievement gaps 
between traditional low performing subgroups and their non-subgroup counterparts. Adequate Yearly Progress (AYP) targets are set with the penultimate expectation that all students are rated as proficient on state report cards by 2013-2014. The feasibility of this expectation is of little consequence as schools must either meet the targets set forth by AYP or face a litany of sanctions levied by state departments of education. Despite the rising popularity of distributed leadership in schools, walking point through this potential educational minefield is the building principal.

Recent literature suggests this accountability may be warranted, at least in part, as there is overwhelming evidence that building principals can positively impact student achievement through their behavior as instructional leaders (Cotton, 2003; Hattie, 2009; Marzano, Waters \& McNulty, 2005; Robinson, 2007). This should come as no surprise to those familiar with Jim Collins' book Good to Great (2001), that examines why some companies make the leap to greatness and others don't. During his research, he continually told his team to ignore the executives, but in the end, the data pointed to specific leadership behaviors as the reason some companies went from good to great and remained there (Collins, 2001).

Because research suggests that effective building principals positively impact student achievement through the instructional leadership behaviors in which they engage - school leadership matters (Cotton, 2003; Hattie, 2009; Marzano, Waters \& McNulty, 2005; Robinson, 2007). Several recent meta-analyses of research on instructional leadership identified the importance of principals using data to monitor student progress and the effectiveness of school practices. Cotton (2003) suggests that "successful principals not only monitor and report student progress data, but they also ensure that findings are used to improve the instructional program" (p. 39). For their book, School Leadership that Works, Marzano, Waters \& McNulty (2005), conducted a meta-analysis 
of 69 school leadership studies which were conducted between 1978 and 2001 that identified 21 responsibilities including "monitoring the effectiveness of school practices and their impact on student learning" (p. 43). In his recent book, Visible Learning, John Hattie (2009) cites a study that established a positive correlation between monitoring the effectiveness of school practices and their impact on student learning with student achievement. Finally, Robinson's (2007) meta-analysis found that principals in higher performing schools put more emphasis on using data for program improvement and monitoring student progress (p. 14). The research is clear that school leadership matters, and one important aspect of school leadership is the principal's use of data to monitor student progress and the effectiveness of the school's curricular, instructional, and assessment practices. The problem is little research exists that examines the relationship between the high school principal's monitoring student progress and student achievement.

\section{Purpose of the Study}

The purpose of this study was to examine the relationship between teacher perceptions of high school principals using data to monitor student progress and student achievement. This should guide the practice of several groups of stakeholders; (1) school principals, (2) district leaders, and (3) state and federal policy makers. School principals will be able to use this research as a resource to build their own capacity to use data in monitoring student progress. District leaders will be able to use this research to develop district policies and expectations for practice based on these results. Finally, state and federal policy makers can use this research to develop and implement policies that support building leaders in their quest to become better instructional leaders by improving their ability to use data in monitoring student progress.

Additionally, the perceptions of high school teachers were compared across student performance groups consisting of low, medium and high. This type of approach 
has been examined before and the results of this study will be compared with the results of previous research.

\section{Research Questions}

The following question will guide the research of this baseline evaluation study:

- RQ1 - Is there a relationship between teacher perceptions of high school principals' monitoring student progress and student achievement as measured by the Performance Index on Ohio's local report card data?

- $\quad$ RQ2 - Is there a relationship between teacher perceptions of standardized testing and student achievement as measured by the Performance Index on Ohio's local report card data?

The proxy for student achievement in this study is the Performance Index (PI) measure for each high school. The PI is a calculation that measures Ohio Graduation Test performance in all subjects based on the number of students at each of five performance levels. The percentage of students at each performance level is multiplied by their respective weight, and the totals for each performance level are summed to arrive at the buildings overall Performance Index score. Teacher perception of monitoring student progress behavior by the principal is operationally defined as how active the principal is perceived to be in each of the following five areas: (1) meeting individually with teachers to discuss student progress, (2) discussing academic performance results with the faculty to identify curricular strengths and weaknesses, (3) using test and other performance measures to assess progress towards school goals, (4) informing teachers of the school's performance results in written form, and (5) informing students of the school's academic progress (Hallinger, 1982). Teachers' perceptions of standardized testing were measured by 11 survey items developed by the researcher and a dissertation committee member. 


\section{Limitations}

There are four limitations associated with this study. First, a possible bias exists as the researcher was recently an employee of the Region 12 State Support Team and is known by some high school principals throughout the region. Second, the results of this study will be generalizable only to schools in southeastern Ohio. The population consists of all high school teachers in Ohio's Region 12. The sample self-selected and is composed of:

(1) school districts and high schools that agreed to participate, and

(2) teachers from those high schools who chose to return the survey. A third limitation is that the data reflected student achievement from 2010-2011. As such it provides only a snapshot of student performance at each school rather than a look at student achievement over a span of time. Fourth, the results of the Principal Instructional Management Rating Scale (PIMRS) are based on teacher perceptions. Although this is the most reliable form of the PIMRS, there are some inherent biases in using teacher perceptions to report principal behavior.

\section{Significance}

Research by Luo (2003) divides leadership into four domains or dimensions which include: (a) instructional leadership; (b) leadership in school vision; (c) school organization operation; and (d) collaborative partnership and larger-context politics. While data can be used effectively in all of these areas, this study focuses on the many ways principals use data in the instructional leadership dimension to monitor student progress, such as:

- to drive improvement in instructional practice (Ohio Leadership Advisory Council, 2008); 
- to assess the impact of school actions on student achievement (Robinson, 2007; OLAC, 2008; Marzano et al., 2005; Cotton, 2003; Hattie, 2009 );

- to make decisions about teaching and learning (OLAC, 2008; Robinson, 2007);

- to engage in an ongoing strategy to improve student performance (OLAC, 2008; Robinson, 2007); and

- to monitor the effectiveness of school practices (Marzano, 2008; Cotton, 2003; Hattie, 2009; Robinson, 2007).

Schools may benefit from the utilization of four different types of data (Bernhardt, 2003):

Demographic data describes the various groups that exist within the school sphere of influence. Commonly, this would include teachers, students, administrators, other school staff, the surrounding community, and various other stakeholder groups.

Student learning data are what most people think of when they hear talk about data. Standardized tests and other high stakes tests would be included in this category as would summative and formative assessments that teachers commonly administer to students.

Perception data are normally gathered through questionnaires, surveys, interviews and focus groups and are important in finding out what the "perceived reality" is about an issue or the school itself.

Finally, school process data include information about school programs, assessment strategies, classroom instruction and other classroom practices. Principal or peer walkthroughs would be a common example of this type of data provided by the administrator, or a colleague spending a brief time "walking through" a teacher's class to observe and record various phenomena. The data from these brief encounters can be 
used to inform and guide teacher practices, curriculum decisions and/or assessment practices or needs.

The pressure to use data in school improvement is emanating from federal, state and local sources. As mentioned previously, the federal No Child Left Behind Act of 2002 has driven education at the state and local levels for the past decade. More recently, Race to the Top Grants have been issued to states by the U.S. Department of Education (USDoE) in order to drive changes in education that will lead to improved student outcomes. One of the expected areas of reform is to create data systems that inform decisions and improve instruction. Ohio, a recent recipient of the Race to the Top Grant, spells out four assurances for participating districts, one of which is using data to improve instruction. School districts participating in Race to the Top are required to have an Instructional Improvement System in place that meets the definition provided by USDoE by 2014 , if they don't have one in place already. The direction of the federal government is clear: they do not want anything to do with schools that aren't using data to improve instruction.

The climate at the state level reflects the pressure applied by the federal government. In order to provide support to local education agencies (LEA's) the Ohio Department of Education (ODE) sponsors at least 24 data tools that are available to districts. Another entity at the state level pushing reform is the Ohio Leadership Advisory Council (OLAC) which is a 50-member panel charged with building a support structure for systemic school improvement and reform. The product of their work is the Ohio Leadership Development Framework (OLDF), which spells out the essential practices in which superintendents and leadership teams need to engage in order to improve outcomes for students. The OLDF highlights in Area 1: Data and the Decision Making Process, the "importance of [building leaders] using data to continuously monitor 
student progress against performance targets and district established goals (OLAC, 2008). ODE's response to the OLDF was to create the Ohio Improvement Process, which is the enactment of OLACs work. In both the Ohio Leadership Development Framework and the Ohio Improvement Process using data to monitor student progress and the effectiveness of school practices is a clear expectation of building leaders. Clearly, Ohio is doing all it can to influence school principals to use data.

At the local level, school boards, superintendents and enlightened communities expect school principals to use data to identify how many of their students are currently achieving at the proficient level and determining what gaps exist between sub-groups and their counter-parts. Monitoring the effectiveness of initiatives aimed at improving student outcomes and student progress has been added to the traditional principal responsibilities of beans, balls and buses (Bernhardt, 2003).

The importance of principal's use of data to monitor student progress is apparent and widely accepted. A quick look at the 2010-2011 Update of the Ohio Data Tools Catalog will show that a total of at least 24 data tools are supported by the Ohio Department of Education. There are at least six student achievement data tools that help answer the question, "how are we doing?" and at least 18 contextual data tools that help to explain those results. In the state of Ohio the data tools are available to monitor student progress. This study examined whether they are being used at the high school level, and if their use is associated with higher levels of student achievement?

\section{Definition of Terms}

1. Actionable knowledge is created when data users synthesize the information, apply their judgment to prioritize it, and weigh the relative merits of possible solutions (Marsh, Pane \& Hamilton, 2006, p. 3). 
2. Adequate Yearly Progress is a measure used to determine the achievement targets for districts and schools (Paige, 2002).

3. Data can be defined as any artifacts that help educators better understand student learning, teaching practices, educational workflow, and other aspects of how districts are run and education is conducted (Wayman, Cho, \& Johnston, 2007, p. 11). Data may be qualitative or quantitative.

4. Data Use can be defined as any practice that brings meaning, information, and knowledge out of data and uses this learning to inform educational practice (Wayman, Cho, \& Johnston, 2007, p. 11).

5. Data Driven Decision-Making refers to teachers, principals, and administrators systematically collecting and analyzing various types of data, to guide a range of decisions to help improve the success of students and schools (Marsh, Pane \& Hamilton, 2006, p. 1).

6. Performance Index (PI) is a calculation that measures achievement/OGT test performance at the 3rd, 4th, 5th, 6th, 7th, 8th, and 10th grade levels based upon the number of students at each performance level (ODE, 2007).

\section{Summary and Organization of the Study}

At no other time in the history of the United States has the academic achievement of all students been so important. Some claim it is a matter of national security that all students leave high school ready for college or the workplace. While improving K-12 public education is a complex and multifaceted process, this study focuses on building capacity in one area that has shown promise in positively impacting academic outcomes for students - the effective use of data by the building principal to monitor student progress. 
This dissertation is presented in five chapters. Chapter One provides an introduction of the proposed study, a statement of the purpose, a list of the research questions guiding the study, a brief description of limitations inherent in this proposed study, the professional significance, a short list of terms and their definitions, a summary and a description of the layout for the rest of the study. Chapter Two consists of a focused literature review beginning with leadership in general, followed by educational leadership ending with the presentation of literature about principals' monitoring student progress. Chapter Three provides an overview of the methods used to carry out this study. Chapter Four describes the sample of the population surveyed for this study and provides a summary of the results of that survey. Finally, Chapter Five synthesizes the results and provides a discussion of what those results mean to the instructional leadership practices of building principals. 


\section{Chapter Two: Review of Literature}

This chapter presents a literature review divided into five sections. The first section provides a brief historical perspective of leadership theory. The second section, presents a review of literature on principal leadership and its impact on student achievement. The third section discusses principal's use of data to monitor the effectiveness of school practices. The fourth section provides a review of what is currently known about principal use of data to make decisions. The final section of this study presents a brief review of literature pertaining to teacher perceptions of standardized testing and the relationship to student achievement.

\section{Leadership Theory}

This review of research on leaders and leadership behaviors borrows from Immegart(1988) and organizes the literature into six divisions consisting of (1) traits of leaders and leadership, (2) styles of leaders and leadership, (3) behavioral studies of leaders and leadership, (4) situational or contingency studies of leadership, (5) studies of transactional leadership, and (6) studies of transformational leadership.

Traits of leaders and leadership. The first studies of leadership examined the traits that set leaders apart from their followers. The belief was either a person had the ability to lead or he didn't, and not much could be done for the have not's. The theories that came out of this belief were called the Great Man Theories of Leadership, noting that today these theories would be Great Man or Woman Theories of Leadership. These theories were based on studying effective leaders and noting that they were different from the people they led. They possessed traits or characteristics that their followers lacked. The popularity of these theories began to decline as research increased in the behavioral sciences (Organ, 1996). 
In the early 1900's the Great Man Theories began to transform into trait theories. Traits in this sense are used to describe characteristics such as capacities, motives or patterns of behavior. The question in trait theory was not whether leaders were born with the traits or acquired them throughout life; the focus was on what traits they possessed that their followers did not. Kirkpatrick and Locke (1991) suggested that these traits consist of drive, leadership motivation, honesty and integrity, self-confidence, cognitive ability and knowledge of the business (Kirkpatrick \& Locke, 1991).

Recent perspectives of the trait theories of leadership include; (1) Achievement Motivation Theory, (2) the Leadership Motive Profile Theory, and (3) Charismatic Leadership Theory. Achievement motivation refers to, "the non-conscious concern for achieving excellence in accomplishments through one's individual efforts." (House \& Aditya, 1997, p. 413) Leaders exhibit high motivation achievement when they set high goals for themselves and take personal responsibility for meeting those goals. They would also be more likely to take risks and be persistent in pursuit of their goals.

The Leader Motive Profile (LMP) Theory postulates that a leader is more likely to be effective if she (1) has a high power motivation, (2) a high concern for the moral exercise of power, and (3) power motivation greater than affiliative motivation (House \& Aditya, 1997). A leader with a low LMP theoretically would be concerned with establishing or maintaining relationships with subordinates and might be less likely to correct or point out sub-par performance when necessary. Conversely, a leader with high LMP would be less concerned with maintaining relationships with subordinates and more concerned that the job was being done in accordance with expectations of performance.

Charismatic leadership is the study of the effects that leaders have on their followers. House, Spangler \& Wocke (1991) describe charismatic leadership as follows: 
Charismatic leaders transform the need, values, preferences, and aspirations of followers. These leaders motivate followers to make significant personal sacrifices in the interest of some mission and to perform above and beyond the call of duty. Followers become less motivated by self-interest and more motivated to serve the interests of the larger collective (p. 364).

Style of leaders and leadership. Following theories focused on traits, leadership research turned to examining the impact of the leader's style on followers. In particular, the leader's degree of boss-centered as compared to subordinate-centered leadership and decision-making was examined. Participative leadership occurs when the leader adopts or utilizes a style whereby he or she shares decision-making authority with other stakeholders. The job of the leader is to determine what style of leadership to employ in certain situations. The leader will choose from a continuum of leadership behavior ranging from boss centered leadership where the manager makes the decision and announces it to the group, to subordinate centered leadership where the manager permits subordinates to make decisions while functioning within limits defined by their superior. As leadership behavior becomes more boss centered the use of authority by the manager increases. Conversely, the amount of freedom for subordinates' increases as the leadership behavior becomes more leadership centered. This relationship is illustrated in Table 2.1 taken from Tannenbaum \& Schmitt (1958). 
Table 2.1 Continuum of Leadership Behavior

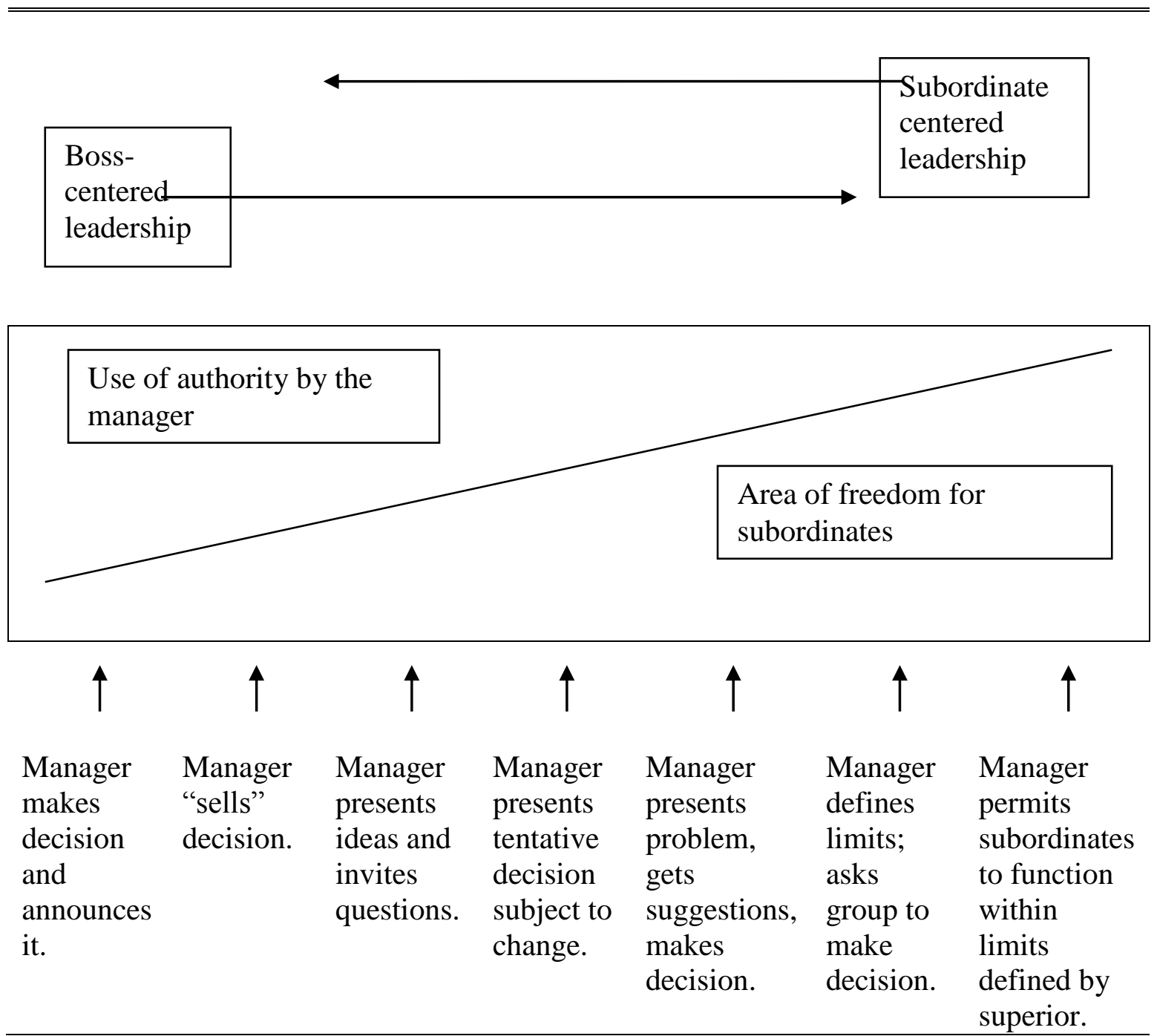

Lewin and colleagues (1939) developed three leadership styles that fall along the continuum described above; (1) autocratic, (2) democratic, and (3) laissez-faire. They conducted experiments with groups of boys in which ninety-five percent of the subjects indicated they preferred democratic over autocratic leadership.

Rensis Likert (1967) also developed leadership styles that utilized the bosscentered to subordinate-centered continuum that consisted of four systems; (1) Level I: 
exploitive authoritative, (2) Level II: benevolent authoritative, (3) Level III: consultative, and (4) Level IV: participative. Likert wrote that "of all the tasks of management, managing the human component is most important," (Likert, 1967, p. 1). Organizations with management systems oriented toward Level IV are more likely to have higher productivity, lower costs, higher earnings and more favorable employee attitudes (Likert, 1967).

Behavioral studies of leaders and leadership. This section of the review of literature serves to segue to the direction leadership research took following the previous 30 years. The early phases of leadership study focused on two domains. The first domain was concerned with the traits leaders possessed that seemed to be lacking in their subordinates. The second domain centered on leadership styles, the most prevalent of these revolving around how authoritarian or democratic the leader was. Throughout these studies on traits and styles the possibility arose that there might not be one particular style that is most effective all the time, but rather it might depend on the contextual factors inherent within a particular organization.

An example of behavioral leadership theory is Blake \& Mouton's (1964) Managerial Grid. In this model, the behavior of the leader is explained focusing on two factors: the leader's concern for people and the leader's concern for productivity. They identify three organizational essentials as, (1) purpose, (2) people, and (3) hierarchy.

Their view of leadership is expressed in the following quote:

The process of achieving organization purpose (the first universal) through the efforts of several people (the second universal) results in some people attaining authority to supervise others; that is, to exercise the responsibility for planning, controlling and directing the activities of others through a hierarchical arrangement (the third universal)." (p. 7)

Blake and Mouton constructed a grid with a horizontal scale and a vertical scale. The leader's concern for people is measured using values from 1 to 9 at the top. The leader's 
concern for productivity is ranked from 1 on the left to 9 on the right. The leader's score then indicates their leadership behavior; for example, 1,1 or 9,9. A 9,9 is the ideal, which indicates a high level of concern for both people and productivity. The basic aim of this leader's behaviors would be to promote conditions that combine elements of creativity, increased productivity and high morale through focused and coordinated team action. This type of model represents a people-oriented model of leadership.

Situational and contingency studies of leaders and leadership. Situational and contingency theories of leadership suggest that effective leaders do not exercise the same leadership in all scenarios, but rather adopt a certain style after considering the context of the situation. Three models of situational leadership that have been studied are (1) Hersey and Blanchard's situational leadership, (2) Vroom and Yetton's normative model, and (3) House's path-goal theory of leadership. This section of the literature review will then conclude with a discussion of Fiedler's contingency theory of leadership.

Hersey and Blanchard's situational leadership. As the study of leadership progressed, researchers began to observe the same style that is effective in one context, may be ineffective in another. This led researchers to develop a theory called situational leadership which postulated that effective leaders take a differentiated approach to leadership; adjusting their style based on characteristics of followers or context. Hersey \& Blanchard's (1969) situational leadership is an example of this model. This view of leadership represented a break from previous studies that focused on either task-oriented or person-oriented approaches to leadership.

Hersey and Blanchard (1969) define leadership as "the process of influencing the activities of an individual or a group in efforts toward goal achievement in a given situation," (p. 60). In other words, they define leadership as the function of the leader, follower and situation, coining the phrase situational leadership. According to these 
researchers, an effective leader is able to adapt her style of leadership to the situation and the needs of the followers. An example of this style would be to use a directive approach with a subordinate with low competence and low commitment toward a task. The corollary would be for the leader to act in a less directive mode with a follower who exhibited high competence and high commitment to the task. Proponents of this leadership style claim that it promotes more self-directed activity from subordinates (Blanchard \& Johnson, 1982).

Vroom and Yetton's normative model. The model developed by Vroom \& Yetton (1973) was intended to determine the most effective degree of participation in decision-making activity (Immegart, 1988). Participation is defined as "a process of joint decision-making by two or more parties (Vroom \& Yetton, 1973, p, 12) As such, this model serves best as a diagnostic tool to inform leadership styles (Immegart, 1988).

House's path-goal theory of leadership. House's Path-Goal Theory of Leadership arose from a need to make sense of research findings that suggested certain leader behaviors or traits were effective in one setting but not another. Up to this point, leadership research was concerned mainly with task-and-people orientation. House (1996) theorized that the effects of leaders' behaviors are contingent upon the situation or context in which the leaders and followers function. Path-goal theory of leadership focuses on the relationship between superiors and subordinates in their day-to-day activities.

Path-goal theory posits that leaders will be effective to the extent that they create affirmative answers to two questions from their subordinates: (1) Can I do this? and (2) Is it worth it? The first question addresses subordinates' degree of belief that they can attain their work goals. The second question addresses subordinates' degree of belief that they will get intrinsic satisfaction and receive valent rewards as a result of attaining their 
work goals (House, 1996). If there are not clear causal linkages to help the leader create affirmative answers to these questions, then it is the leader's responsibility to create that linkage. Finally, it is the responsibility of the leader to ensure that subordinates have the resources, skills or support necessary to be successful.

Fiedler's contingency model of leader effectiveness. Similar to situational leadership, Fred Fiedler posited that leader effectiveness is contingent upon the composition of the group that they lead. Fiedler (1967) created three groups and then examined which leadership functions work most effectively with each group. The effectiveness of a group depends upon the interaction between the leader's style of relating to his group members, and the degree to which the situation enables the leader to exert influence over his group (Fiedler, 1967). Table 1.1 illustrates Fiedler's model Table 2.1

Fiedler's Model of Leader Effectiveness

\begin{tabular}{lll}
\multicolumn{1}{c}{$\begin{array}{c}\text { Interacting } \\
\text { Groups }\end{array}$} & \multicolumn{1}{c}{$\begin{array}{c}\text { Co-acting } \\
\text { Groups }\end{array}$} & Counteracting Groups \\
\hline Directing & $\begin{array}{l}\text { Development of individual } \\
\text { group-member motivation }\end{array}$ & Maintain the group \\
Channeling & $\begin{array}{l}\text { Individual training to } \\
\text { enable each group member } \\
\text { to perform to his ability }\end{array}$ & $\begin{array}{l}\text { Facilitate communication } \\
\text { and mutual understanding }\end{array}$ \\
& $\begin{array}{l}\text { Prevention of destructive } \\
\text { rivalries and competition }\end{array}$ & $\begin{array}{l}\text { Establish a climate } \\
\text { conducive to the } \\
\text { development of creative } \\
\text { solutions to the problem }\end{array}$ \\
& & \\
Guiding & & \\
Tuning & & \\
\hline
\end{tabular}


Transactional leadership. Transactional leadership theorizes that effective leaders do the following two things well: (1) reward subordinates contingently based on performance, and (2) actively manage by exception. This leadership style focuses on the exchange between parties. This exchange is based upon the leader discussing and specifying the rewards and conditions for fulfilling the requirements (Avolio \& Bass, 2002).

Transformational Leadership. Transformational leadership focuses on four practices sometimes referred to as the "Four I's of Transformational Leadership":

- idealized and inspiring;

- intellectually stimulating;

- individually considerate; and

- inspirationally motivating.

Transformational leadership is an expansion of transactional leadership and can be authoritative or democratic; directive or non-directive. Transformational leaders convert their followers into leaders and they transcend their own interests in order to benefit the organization and to meet the challenge of the task or mission. (Avolio \& Bass, 2002)

\section{Principal Leadership}

The emphasis on the instructional leadership component of the principalship began with the effective schools' research that will be explained below in further detail. Multiple research studies on common correlates of effective schools showed certain principal-controlled correlates that were common among the identified effective schools. These include principals who focus on (1) creating a learning climate free of disruption, (2) a system of clear teaching objectives, and (3) high achievement for all students. (Hattie, 2009) This review of instructional leadership is divided into three sections: the first section gives a brief overview of the research, results and limitations of the effective 
schools research. The second section, describes some of the studies that focused on ascertaining what impact building principals have on student outcomes. The final section informs the reader concerning recent syntheses and meta-analytic research that has been conducted in an attempt to inform practitioners of the highest leverage principal leadership behaviors.

Effective schools research. This historical perspective of instructional leadership research begins with the effective schools research from the 1970's and 1980's. This research was conducted as a response to James Coleman's 1966 report, the Equality of Educational Opportunity Study. Coleman's research suggested that (1) the most powerful variable in student learning is the student's family and background, and (2) there was little a school could do to overcome the negative effects of this variable. Ronald Edmonds (1979), in particular took exception to this stance that students from low socioeconomic status (SES) families were incapable of learning at high levels as did Brookover \& Lezotte (1977). Much of this research focused on schools that were having success educating low SES and/or minority students and sought to discover what attributes these schools had in common. The following correlates of effective schools were identified throughout this period of research: (1) strong instructional leadership, (2) strong sense of mission, (3) demonstrated, effective instructional behaviors, (4) high expectations for all students, (5) frequent monitoring of student achievement, and (6) a safe and orderly environment (Edmonds, 1979; Brookover \& Lezotte, 1977; Lezotte, n.d.). It is important to note that this research did not focus on the effects of principal leadership on student achievement, only on what correlates existed among effective schools (Hallinger \& Heck, 1996).

The effective schools research was a powerful force in public education and still has momentum today (Lezotte, n.d.), but there were critics of these studies and the 
conclusions that policy makers were drawing from the results. Criticism of the effective schools research centered on the methods used in the studies and the implications of the research (Purkey \& Smith, 1983). One concern was that most of the schools in the effective schools research were urban elementary schools serving minority and/or low SES students. This narrow, and relatively small sample, limited the generalizability of the findings to other school settings. There is no guarantee that what is effective in one setting will get the same results in another setting and this segues into the next criticism which was the implications of this research. These studies boiled effective school practices into a neat list of correlates, which if present in the school setting, would supposedly lead to success. Critics of the implications of the effective schools research maintained that this was oversimplified and that there were many more factors besides the correlates that go into creating an effective school (Purkey \& Smith, 1983).

Principal effects on student achievement. Despite the progress made in identifying correlates of effective schools, such as high expectations for all students and more specific instructional leadership behaviors as monitoring student progress, the findings were still very broad and open to interpretation by the practitioner. In light of this, Hallinger and Murphy (1985) developed a framework that provided a research-based definition of the principal's role as instructional leader. Their model divided the instructional leadership role into three parts; (1) defining the school mission, (2) managing the instructional program, and (3) promoting a positive learning climate. These three divisions were subdivided into more specific and narrowly defined job functions. From this model, Hallinger developed the Principal Instructional Management Rating Scale (PIMRS) which was used in the Hallinger \& Murphy study and over 100 studies of instructional leadership since its inception. Hallinger \& Murphy (1985) used the PIMRS to measure instructional leadership at ten elementary schools within a single 
school district. The instrument was appraised in content validity, reliability, validity, and construct validity and these results will be discussed in a later chapter.

The next phase in the instructional leadership research was the attempt to link principal instructional leadership to student achievement. Andrews \& Soder (1987) provide an example of this line of inquiry in their study of the relationship between principal leadership and student achievement. Specifically, they studied the following roles of the school principal and the associated effect on student achievement: (1) resource provider; (2) instructional resource; (3) communicator; and (4) visible presence. Their findings suggested that teacher perception of the principal as an instructional leader were critical to the reading and mathematics achievement of students, especially among low achievers (Andrews \& Soder, 1987).

In discussing the research examining the link between principal leadership and student achievement, one important question to be answered is, "How do principals affect student achievement?" Hallinger \& Heck (1998) provide a useful framework for categorizing studies based on how they attempt to demonstrate an answer for that question. For their review they selected 41 studies that were attempting to demonstrate a link between principal leadership and student achievement. They divided the studies into five models: direct-effects; direct, with antecedent effects; mediated-effects; mediated, with antecedent effects; and reciprocal-effects. This review and the models contained therein are important to this literature review because they capture the general trend of principal leadership research between 1980 and 1995.

Researchers using a direct-effect model are trying to demonstrate how a principal's actions influence school outcomes. This model has not shown much promise in producing positive results linking principal leadership to student achievement, although this design was the most common one used in principal-effect studies prior to 
1987. A weakness of this model is that the relationship between principal leadership and student achievement is tested, but even when positive results occur, little information about how the results actually came about is provided (Hallinger \& Heck, 1998).

A second model utilized to study the principal-student achievement link is the mediated-effects model. Researchers using this model hypothesize that principal effects are achieved through the impact that their actions have on others. These studies have produced consistent evidence that principal leadership positively affects student achievement. This model becomes even stronger when combined with antecedent variables (Hallinger \& Heck, 1998).

A third model used to examine the link between principal leadership and student achievement is the reciprocal-effects model. Researchers using this model hypothesize that teachers affect principals, just as principals affect teachers, and the processes by which this is occurring affect student outcomes. There are not enough studies to validate this model and none included in the Hallinger \& Heck (1998) review were specifically designed to utilize this model.

In conclusion, the most promising model for studying the principal-student achievement link during the period of 1980-1995 was the mediated, with antecedenteffects model. This suggests that principal effects on student achievement are indirect and mediated through others on whom they have an effect, such as teachers. This period of research was important in that it shifted the focus from behaviors of principals in effective schools to what actual effects these principal behaviors have on student achievement, and what is the best way to measure these effects. As we will see in the next section, this is important groundwork for later meta-analyses that more conclusively demonstrate the link between principal leadership and student achievement. 
Syntheses and meta-analytic research. The third and current phase of research on principal leadership features a number of syntheses and meta-analyses that attempt to synthesize principal leadership practices that have been shown to have a positive impact on student outcomes. Some of these studies also attempt to quantify the effect of principal leadership on one or more student outcomes. This section of the review of literature will briefly describe three syntheses of principal leadership and four metaanalyses of principal leadership.

Syntheses. Kathleen Cotton (2003) provided a narrative analysis of 81 principal leadership studies spanning the time period of 1970-2003, focusing mainly on the latter fifteen years of that period. Cotton focused on research that studied principal behaviors in relation to student achievement. The majority of the studies used in this synthesis were primary sources studying principal leadership. Cotton's synthesis isolated 25 principal leadership characteristics and/or behaviors that research suggests positively impact student outcomes. These characteristics and behaviors are illustrated in table 1. In her review, Cotton assimilated key research points for each of the 25 behaviors and/or characteristics of effective principal leadership, and explained each in detail (Cotton, 2003).

Kenneth Leithwood and colleagues (Leithwood et. al., 2004; Leithwood et. al. 2006) provide two more reviews that help to compartmentalize and support Cotton's (2003) work. These reviews conclude that there is a common set of basic leadership practices that are present in high achieving schools. These "basics" are listed below and may be manifested differently in different contexts:

1. setting the direction and building a vision;

2. understanding and developing people;

3. redesigning the organization; and 
4. managing the learning and teaching program.

One could liken these basics to the wheels on an automobile. The automobile is a complex piece of machinery with many moving and interdependent parts, but without wheels this magnificent piece of machinery goes nowhere. These four basics are like the wheels of education. Schools also are complex systems with many moving and interdependent parts, but these basics need to be present in order for the school to move forward. In fact, Leithwood and colleagues lend support to the preceding analogy with the following, "As far as we are aware, there is not a single documented case of a school successfully turning around its pupil achievement trajectory in the absence of talented leadership." (Leithwood et. al., 2006, p. 5)

Both of Leithwood's reviews were based on five sources of evidence lending support for the importance of these basics: (a) case studies, (b) large scale quantitative studies of overall leader effects, (c) recent large scale meta-analyses, (d) studies on effects of leadership on pupil engagement, and (e) leadership succession research (Leithwood et. al., 2004; Leithwood et. al., 2006).

Meta-analyses. As with any field of academic study, the study of education in general, and specifically principal leadership, presents challenges and obstacles that must be overcome. Especially in education, research findings are only important if they impact the practice of those in the field, or impact the policies that guide those in the field. The meta-analysis, a recently utilized research method, is doing just that. Glass (1976) explains the meta-analysis:

The statistical analysis of a large collection of analysis results from individual studies for the purpose of integrating the findings. It connotes a rigorous alternative to the casual, narrative discussion of research studies which typifies our attempts to make sense of the rapidly expanding research literature. (p.3) 
One weakness in educational research is the difficulty of designing studies that have a high degree of generalizability. This presents a problem in education because schools are highly contextual and therefore school leadership has been shown also to be highly contextual (Hallinger \& Murphy, 1986). Another obstacle to quantitative research in education is the difficulty in establishing the conditions for proper experimental design (Marzano, Waters \& McNulty, 2005). As Glass (1976) explains, narrative reviews often lack the rigor that should be required to use findings to guide practice and policy. The meta-analysis provides a step for researchers to hurdle many of the obstacles that stand in the way of meaningful educational research. This literature review will discuss the findings of three meta-analyses that are having an impact on the policy and practice of public education at the PK - 12 levels.

Marzano, Waters \& McNulty (2005) conducted an influential meta-analysis on school leadership and its impact on student achievement that examined 69 studies completed or published between 1978 and 2001. The number of schools involved in this study was 2802 with an estimated 14,000 teachers and 1.4 million students. The authors were attempting to synthesize the previous 35 years of research on principal leadership and illustrate that school leadership is important to student achievement. The studies included in this meta-analysis utilized questionnaires about different principal leadership behaviors. These questionnaires were administered to teachers, and the average score from each school was correlated with student achievement of each school and then they computed 69 different correlations on a variety of principal leadership behaviors and student achievement. This meta-analysis produced an average correlation between principal leadership behavior and student achievement of .25. The authors identified 21 Responsibilities of the School Leader and provided average correlations for each 
responsibility. The list, illustrated in Table 2.2 is similar to the list Cotton (2003)

developed with her narrative review.

Table 2.2

The 21 Responsibilities of the School Leader

\begin{tabular}{|c|c|}
\hline Responsibility & Description \\
\hline Affirmation & $\begin{array}{l}\text { Recognizes and celebrates accomplishments and } \\
\text { acknowledges failures }\end{array}$ \\
\hline Change Agent & $\begin{array}{l}\text { Is willing to challenge and actively challenges the status } \\
\text { quo }\end{array}$ \\
\hline Contingent Rewards & Recognizes and rewards individual accomplishments \\
\hline Communication & $\begin{array}{l}\text { Establishes strong lines of communication with and } \\
\text { among teachers and students }\end{array}$ \\
\hline Culture & $\begin{array}{l}\text { Fosters shared beliefs and a sense of community and } \\
\text { cooperation }\end{array}$ \\
\hline Discipline & $\begin{array}{l}\text { Protects teachers from issues and influences that would } \\
\text { detract from their teaching time or focus }\end{array}$ \\
\hline Flexibility & $\begin{array}{l}\text { Adapts his or her leadership behavior to the needs of the } \\
\text { current situation and is comfortable with dissent }\end{array}$ \\
\hline Focus & $\begin{array}{l}\text { Establishes clear goals and keeps those goals in the } \\
\text { forefront of the school's attention }\end{array}$ \\
\hline Ideals/Beliefs & $\begin{array}{l}\text { Communicates and operates from strong ideals and beliefs } \\
\text { about schooling }\end{array}$ \\
\hline Input & $\begin{array}{l}\text { Involves teachers in the design and implementation of } \\
\text { important decisions and policies }\end{array}$ \\
\hline Intellectual Stimulation & $\begin{array}{l}\text { Ensures faculty and staff are aware of the most current } \\
\text { theories and practices and makes the discussion of these a } \\
\text { regular aspect of the school's culture }\end{array}$ \\
\hline $\begin{array}{l}\text { Involvement in Curriculum, } \\
\text { Instruction and Assessment }\end{array}$ & $\begin{array}{l}\text { Is directly involved in the design and implementation of } \\
\text { curriculum, instruction, and assessment practices }\end{array}$ \\
\hline $\begin{array}{l}\text { Knowledge of Curriculum, } \\
\text { Instruction and Assessment }\end{array}$ & $\begin{array}{l}\text { Is knowledgeable about current curriculum, instruction } \\
\text { and assessment practices }\end{array}$ \\
\hline Monitoring/Evaluating & $\begin{array}{l}\text { Monitors the effectiveness of school practices and their } \\
\text { impact on student learning }\end{array}$ \\
\hline Optimizer & Inspires and leads new and challenging innovations \\
\hline Order & $\begin{array}{l}\text { Establishes a set of standard operating procedures and } \\
\text { routines }\end{array}$ \\
\hline Outreach & $\begin{array}{l}\text { Is an advocate and spokesperson for the school to all } \\
\text { stakeholders }\end{array}$ \\
\hline Relationships & $\begin{array}{l}\text { Demonstrates an awareness of the personal aspects of } \\
\text { teachers and staff }\end{array}$ \\
\hline Resources & $\begin{array}{l}\text { Provides teachers with materials and professional } \\
\text { development necessary for the successful execution of } \\
\text { their jobs }\end{array}$ \\
\hline Situational Awareness & $\begin{array}{l}\text { Is aware of the details and undercurrents in the running of } \\
\text { the school and uses this information to address current and }\end{array}$ \\
\hline
\end{tabular}


Table 2.2

The 21 Responsibilities of the School Leader

\begin{tabular}{ll}
\hline \multicolumn{1}{c}{ Responsibility } & \multicolumn{1}{c}{ Description } \\
\hline \multirow{2}{*}{ Visibility } & potential problems. \\
& $\begin{array}{l}\text { Has quality contact ad interactions with teachers and } \\
\text { students }\end{array}$ \\
\hline
\end{tabular}

Another important meta-analysis in recent literature comes from Viviane Robinson (2007) who identified leadership dimensions that made the biggest difference in student outcomes and explained why they make that difference. Her meta-analysis included 11 studies published in English speaking journals that empirically examine the links between leadership and student outcomes. This meta-analysis identified 198 behaviors which she grouped into five Leadership Dimensions. These dimensions are related groups of principal leadership practices impacting student outcomes. The Leadership Dimensions that Robinson identified are (more detail is provided in Table 2.3):

1. establishing goals and expectations;

2. strategic resourcing;

3. planning, coordinating and evaluating teaching and the curriculum;

4. promoting and participating in teacher learning and development; and

5. ensuring an orderly and supportive environment.

Establishing Goals and Expectations had an average effect size of .35 which Robinson interpreted as small but educationally significant. This dimension includes setting clear goals that are academically focused and then placing emphasis on these goals by ensuring that they are embedded into school and classroom routines and procedures. This dimension also includes communicating the goals and expectations to 
all, informing the community of academic accomplishments, and recognizing student achievement (Robinson, 2007).

Strategic Resourcing refers to securing resources that are aligned to pedagogical purposes. This would be in contrast to simply securing resources by chasing initiatives that tend to dissipate the necessary focus on the educational program. The most important resource that principals may or may not have control over is staffing. Robinson found that schools where the principals emphasized academically-focused goals and had control over selecting their teaching staff, were typically higher achieving than when those factors were not in place. This dimension also includes the importance of a coherent program built around a common set of principals and key ideas, specific strategies for teaching and assessment, and school organizations that support coherence in staff recruitment, evaluation and professional development (Robinson, 2007).

Planning, Coordinating and Evaluating Teaching and the Curriculum yielded a small-to-moderate impact on student achievement. This dimension includes three subdimensions: First is active oversight and coordination of the instructional program. Second is the degree of leader involvement in classroom observation and subsequent feedback. Third is a greater emphasis on ensuring that staff systematically monitored student progress. Robinson defines this third sub-dimension as "teacher use of data to evaluate student progress, adjust their teaching, plan their weekly programme and give students feedback in reading and mathematics" (Robinson, 2007, p. 14).

Promoting and Participating in Teacher Learning and Development is more than just procuring high quality professional development opportunities for teachers and staff. This dimension identifies the importance of actively participating in teacher learning and development. Another important leadership behavior that comprises this dimension is promoting and participating in staff discussions of teaching and teacher problems. A 
third area addressed in this dimension is the important role of the principal as a source of instructional advice for staff. This dimension had by far the biggest effect size, .84 , which lends support for this dimension to be taken seriously by those in the field and those who create policy (Robinson, 2007).

Ensuring an Orderly and Supportive Environment is the fifth leadership dimension identified by Robinson and had an effect size of .27. Principals who exhibit behaviors in this dimension encourage a school environment of cultural understanding and respect for differences, while providing a safe and orderly environment with a clear discipline code enforced through respectful relationships and clearly and consistently enforced. Another important aspect of this dimension is the principal's role in protecting teachers from interruptions in teaching time and from undue pressure from parents or other officials (Robinson, 2007).

Over the last 30 years there has been a substantial interest in the role principal leadership may or may not play in ensuring high academic achievement for students. Both quantitative and qualitative methods have been applied to the question using numerous research methods. The results have been consistent over this period of time: instructional leadership, setting of goals and developing and communicating a mission and vision, and the importance of a positive climate with a supportive and orderly learning environment have been identified as principal leadership behaviors that have a positive impact on student achievement (Cotton, 2003; Edmonds, 1979; Hallinger \& Murphy, 1985; Leithwood et. al., 2004; Leithwood et. al., 2006; Marzano, Waters \& McNulty, 2005; Robinson, 2007; Robinson, Lloyd \& Rowe, 2008). 
Table 2.3

Leadership Dimensions from 11 Studies of Effects of Leadership on Student Outcomes (Robinson, 2007)

Leadership Dimension

1. Establishing goals and expectations teaching and the curriculum

2. Strategic Resourcing
Meaning of Dimension

Includes the setting, communicating and monitoring of learning goals, standards and expectations, and the involvement of staff and others in the process, so that there is clarity and consensus about goals.

Involves aligning resource selection and allocation to priority teaching goals. Includes provision of appropriate expertise through staff recruitment.

Direct involvement in the support and evaluation of teaching through regular classroom visits and the provision of formative and summative feedback to teachers. Direct oversight of curriculum through school-wide coordination across classes and year levels and alignment to school goals.

4. Promoting and participating in teacher learning and development

Leadership that not only promotes, but directly participates with teachers in, formal or informal professional training.

5. Ensuring an orderly and supportive environment
Protecting time for teaching and learning

by reducing external pressures and interruptions and establishing an orderly and supportive environment both inside and outside classrooms.
Average ES $=0.35$

( $\mathrm{SE}=.08)$

49 effect sizes from 7 studies

Average $\mathrm{ES}=0.34$

$(\mathrm{SE}=.09)$

11 effect sizes from 7 studies

Average $\mathrm{ES}=0.42$

$(\mathrm{SE}=.07)$

79 effect sizes from 7 studies

Average $\mathrm{ES}=0.84$

( $\mathrm{SE}=.14)$

17 effect sizes from 6 studies

Average ES $=0.27$

( $\mathrm{SE}=.09$ )

42 effect sizes from 8 studies 
Instructional leadership versus transformational leadership. This literature

review was written with a conscious decision to refer to the leadership behaviors of the principal as principal leadership rather than choose one of the two broad models of principal leadership prevalent in the research of the last 30 years: Instructional Leadership and Transformational Leadership. The instructional leadership model of principal leadership focuses mainly on coordinating, supervising, and developing curriculum and instruction (Hallinger, 2003). The transformational model of leadership focuses on developing the capacity of followers and inspiring them to higher levels of personal commitment to organizational goals (Leithwood, 1999). There are three reasons supporting the decision to use the broader term principal leadership rather than a narrower model:

- First, in general, abstract or broad theories of leadership have not been useful in guiding principals to enact specific leadership practices that impact student achievement (Robinson, Lloyd \& Rowe, 2008). Instructional leadership has been associated with a task-oriented focus of the principal while transformational leadership has been associated with a relationship-oriented focus.

- Another reason this literature review eschews the instructional leadership transformational leadership dichotomy is "effective leaders do not get the relationships right and then tackle the educational challenges - they incorporate both sets of constraints into their problem solving" (Robinson, Lloyd \& Rowe, 2008).

- Finally, related to the previous point, research suggests that when teachers perceive the principal's instructional leadership to be appropriate, they grow in 
commitment, professional involvement and willingness to innovate (Marks \& Printy, 2003). In other words, these models to not exist in silos; good principals need to have elements of each of these models in order to be effective leaders.

\section{Principals Monitoring Student Progress}

An examination of the school leadership research over the last 30 years reveals several consistent patterns. The frequent and careful monitoring of student progress is one of these patterns; this includes both the monitoring behaviors of the principal and the degree that the principal ensures that staff monitor student progress (Cotton, 2003). Hallinger \& Murphy (1985), in creating their Principal Instructional Management Rating Scale include five principal behaviors in the subscale Monitor Student Progress. These specific principal behaviors are listed below and relevant support from the literature is provided for each.

Meet individually with teachers to discuss student progress. It is plainly clear from the literature that effective schools have means by which teachers and principals are able to monitor student progress. School leadership bears the burden of ensuring that teachers are tracking the learning of their students and that open and frequent discussions about instruction are held (Blasé \& Blasé, 1999; Cotton, 2003; Edmonds, 1979).

Robinson (2007) found that in higher achieving schools the principal and staff worked together to review and improve teaching.

In a study by The Education Trust (2005), researchers compared practices of high impact and low impact high schools in five key areas: (1) school culture, (2) academic core, (3) support for all students, (4) teachers, and (5) organizing instruction. All schools in the study had access to assessment data, but principals at high impact schools met with 
teachers to discuss student progress. One principal at a high impact school met individually with each teacher and had them write a plan on how to improve on weaknesses revealed in the data. On the other hand, one average impact principal stated that she made copies of the data and placed them in faculty mailboxes with the expectations that they would discuss the data in their next department meeting.

Discuss academic performance results with the faculty to identify curricular strengths and weakness. This behavior could take the form of examining lesson plans, conducting a walk-through or looking at student work (Southworth, 2002). Fullan (2008) writes that in order to model instructional leadership school principals should lead discussions around the progress of the school toward school goals. A common theme of leadership taking a more direct role in coordinating the curriculum vertically is apparent in high performing schools, with principals leading the development of a progression of teaching objectives across grade levels (Robinson, 2007). Finally, Marzano, Waters \& McNulty (2005) concluded from their meta-analysis that monitoring the effectiveness of the school's curricular, instructional and assessment practices are part of the behaviors associated with effective school leadership.

\section{Use tests and other performance measures to assess progress toward school}

goals. Leithwood et al. (2004) found that the systematic use of student testing data for district planning was identified as a characteristic of academically effective school districts. Similarly, higher student achievement was found in schools where teachers conducted an in-depth analysis of assessment information to guide instruction (Robinson, 2007) Using tests and other performance measures is not only important in evaluating 
pupil, class and school levels of performance and progress (Southworth, 2002) but should also be used to identify and celebrate successes (Cotton, 2003).

In The Education Trust (2005) study, high impact schools developed early warning systems. The progress of students was monitored on a regular basis (weekly for instance) so that interventions could be administered before students fell too far behind. Support systems were also found to be more formal and systematic in high impact schools as they found ways to extend learning time for struggling students through outside vendors, Saturday school and guaranteeing transportation (The Education Trust, 2005).

\section{Inform teachers of the school's performance results in written form.}

Hallinger and Murphy (1985) found that an important aspect of instructional leadership included school leaders presenting written reports of school assessment results in a timely fashion. Principal-led, school wide examination of data has been found to be associated with a significant influence on student achievement (Robinson, 2007). Cotton (2000) also identified making student performance data available to all staff for use in planning, an important school practice. The Education Trust (2005) study referenced above also found that high impact administrators communicated test score information more formally than average impact administrators.

Inform students of the school's academic progress. Research on this aspect of school leadership behavior is scant, but Hallinger \& Murphy (1985) suggest that principals who maintain a student-centered focus are perceived by teachers and supervisors as the strongest instructional leaders. 
Hamilton et al. (2009) found that providing instruction to students on how to use their own achievement data to monitor their progress led to increased motivation for secondary school students. The authors cite three reasons for this: (1) this process forces students to map out attainable accomplishments; (2) it reveals to the students actual achievement gains; and (3) it provides the student a sense of control over their own outcomes (Hamilton et al., 2009).

\section{Data Utilization}

Effective data practices are interdependent among the classroom, school and district levels. The Education Trust (2005) found significant differences in the ways high-impact and average-impact high schools use data. In the high-impact schools, data was used more formally and a greater effort was made to use data to improve curriculum and instruction. The current reality in many schools can be summed up in the words of education author and researcher Brian McNulty, "The end result is that we have a bunch of data; we don't know what it means or what to do with it" (B. McNulty, personal communication, May 12, 2011). The following section of this literature review will discuss the importance of data use by school principals, what type of data they use, what they use that data for and what some of the facilitators and barriers are for data use by school principals.

Importance of data utilization by the school principal. The literature suggests that the school principal role is central to building systems and capacity so that educators know what data means and they know what to do with it. The following quote from Deitke (2009) illustrates this view, "Advanced learning requires the principal to lead, ensuring that data are used effectively to determine if students in the school are learning" 
(p. 39). Supovitz \& Klein (2003) summed up their findings on the importance of the building principal in using data to guide student performance as follows:

Virtually every example of innovative data use in this study came from the initiative and enterprise of an individual who had the vision and persistence to turn a powerful idea into an action...leaders breathed meaning into their data...In most cases, it was the building principal who was the driving force behind strong data use (p. 36).

Mason (2002) found that strong leadership supporting data use was crucial in two ways;

(1) by helping to create a school culture that accepts the use of data, and (2) creating a culture that views data as information with the means to aid in problem solving and knowledge-building. At the same time, in addition to strong leadership, teams with broad representations of administrators, teachers and other staff were more successful in establishing effective data practice (Mason, 2002).

The data used to drive instruction. The importance of school principals utilizing data to monitor student progress and inform instruction is clear. This section seeks to describe what data principals are currently using to accomplish this by examining three main categories; (1) external achievement data, (2) school or district wide internal assessment data and (3) individual teacher assessments (Supovitz \& Klein, 2003).

External achievement data was the most commonly used data by principals (Marsh, Pane \& Hamilton, 2006; Deike, 2009) with most of this type of data consisting of state mandated assessment scores. These were not perceived to be as effective as internal assessments by school leaders (Wayman, Brewer \& Stringfield, 2009). This perceived lack of effectiveness has driven the effort to create or adopt local tests given frequently 
throughout the year and may be more effective for monitoring student progress towards state standards than external assessments (Marsh et al., 2006).

Internal assessments in districts and schools consist of commonly developed or adopted assessments that are given with some frequency throughout the school year. Examples of these would include common formative assessments (CFA's), interim or progress tests, quarterly exams and the like. Principals reported that progress or interim tests, aligned to the standards were moderately to very useful for guiding decisionmaking about instruction (Marsh et al., 2006).

Although principals perceive these assessments to be more effective for monitoring student progress than external assessments, teachers prefer an even more granular view. In one district included in the same study, Marsh et al. (2006) reported that over $60 \%$ of teachers indicated that classroom assessments are more useful than district quarterly tests for driving decisions about instruction.

It is apparent that there are role-driven differences in the data educators prefer to rely on for instructional decisions. Increasingly granular views are desired the closer one get to the classroom. These findings suggest the need for a balanced system of assessments as Stiggins, Arter Chappuis \& Chappius (2006) advocate.

How principals use data. Principals are using data in various ways which will be discussed here. For the purposed of this literature review the ways principals are using data are divided into two major categories; to focus conversations around the improvement of instruction and to monitor schools, teachers and students. This section will end with a brief discussion of how principal data use varies within and between schools and by grade level. 
The most common reason principals are using data is to focus conversations around the improvement of instruction (Wayman et al., 2007; Wayman et al., 2009). A survey of school leaders conducted by the Consortium for Policy Research in Education (CPRE) indicated that $84 \%$ of the respondents strongly agreed and $16 \%$ somewhat agreed that student performance data are an important source to inform classroom instruction (Supovitz \& Klein, 2003). These conversations around the improvement of instruction fall into five categories: (1) informing instruction and practices, (2) early communication, (3) collaborative communication, (4) supporting evidence in conversations with parents, and (5) conversations resulting in teacher leadership (Supovitz \& Klein, 2003).

Wayman et al. (2007) reported that in their interviews with administrators concerning how they used data, most of the administrators comments were about how they used data to respond to the individual needs of students. Administrators also used data to build collaborative conversations and teacher leadership (Wayman et al., 2009). Using data as a source of evidence in supporting conversations with parents about their child's achievement or lack thereof was reported in Marsh et al. (2006).

The other broad category of data use by administrators is in the monitoring of schools, teachers and students (Marsh et al., 2006). Efforts to better serve low performing students are highly dependent upon better analysis and monitoring of student performance data (Supovitz \& Klein, 2003). Setting improvement goals is another use of data by administrators found in the literature (Marsh, et al., 2006;Supovitz \& Klein, 2003). As mentioned earlier in this literature review, tests or other assessments given frequently throughout the year are more effective for monitoring student progress than quarterly or interim progress tests. 
The variance of data utilization between and within schools and between grade levels is the final topic of this section of the literature review. Concerning this, Deike (2009) found that while all the elementary principals she studied used data to monitor student progress in math and reading, only a few secondary principals did so. High school teachers in Wayman et al. (2007) scored lower on survey questions about data culture and data use. Interestingly, there was more variation reported between schools than within schools (Marsh, et al., 2006) which would indicate the lack of systemic data use in schools.

\section{Barriers and facilitators of data use by school principals. Educational} research and author Mike Schmoker (2008) writes, "For data-driven instruction to transform schooling - which it can - it must serve as master very different from rigid accountability formulas" (p. 70). This quote brings to light the dirty little secret that to use data to monitor student progress and drive instruction can run counter to the way teachers have traditionally done their job, especially at the secondary level (Wayman, et al., 2007). Many principals lack adequate preparation in using data to drive instruction (Wayman, et al., 2007). Finally, access to the right data has served as a barrier to effective data use (Wayman, et al., 2007).

Facilitators that support data use by school principals include both formal and informal structures. Some formal structures would include both new and already existing structures; staff professional development days for instance. It would also include data use centered on specific and measurable goals. Informal structures include using data in a non-threatening way and structures that encourage collaborative work (Wayman et al., 2009). 


\section{Teacher Perceptions of Standardized Testing}

This section reviews pertinent literature on teacher perceptions of standardized testing. This will be presented in three parts; (1) general overall perception, (2) perception of teachers' preparing students for the tests, and (3) teacher perception of the impact on student achievement. It goes without saying that; overall, teachers do not have a favorable perception of the No Child Left Behind Act of 2002 or the standardized assessments that accompanied that legislation (Mertler, 2010). Criticisms of standardized testing have been in the literature for at least the last 20 years. Paris (1992) and Sheppard (1991) leveled the following criticisms, pulled from their research, that the standardized testing movement was having the following impacts on public schooling:

- reduction in teacher creativity;

- teachers teaching to the test;

- lost class time from test preparation and administration; and

- neglect of higher order thinking skills.

This negative overall perception was prevalent with National Board Certified Teachers (NBCT) in Ohio also. In Rapp (2001), the research suggested that NBCTs in Ohio perceived the state's tests to be harmful to the educational process.

Standardized testing has had an impact on the preparation of students according to Mertler (2010). This research indicated that three-fourths of their sample of Ohio teachers indicated that NCLB (2002) had forced them to change the ways in which they assessed their student's academic performance. Additionally, $80 \%$ indicated that they spent more time throughout the year preparing students for state tests. In comparing elementary teachers and secondary teachers, Mertler's (2010) results suggested that 
elementary teachers are doing more to prepare students and are making more instructional changes due to testing than are secondary teachers.

Given that teacher's perceptions of standardized testing are so negative, one might conclude there is a negative relationship between teacher attitudes towards testing and student performance. This relationship has not played out in the literature. Mulvenon, Stegman \& Ritter (2005) tested the hypothesis that teacher attitudes towards standardized testing are associated with student performance on those exams. Mulvenon et al. failed to find a significant relationship between teacher attitudes and student performance using regression analysis. Lai \& Waltman (2008) also reported that their research suggested that teacher perceptions of standardized testing did not vary across academic achievement levels. 


\section{Chapter Three: Methods}

The main problem addressed in this study was the lack of research examining the relationship between high school principals' monitoring student progress and student achievement. Monitoring student progress has been consistently identified, over the last 30 years, as a key component of effective instructional leadership of the school principal. This chapter describes the design of this baseline study (Edmonds, 1979; Hallinger \& Murphy, 1985; Leithwood et al., 2006; Marzano, Waters \& McNulty, 2005; Robinson, 2007). It begins with a brief restatement of the problem and a discussion of its significance. Next, is a description of the population and sample followed by information about the instrumentation used in this study. Then, the procedures used to collect and analyze the data are explained. The chapter ends with a guarantee of anonymity and confidentiality.

\section{Restatement of the Problem}

Principals in school buildings across this nation and perhaps throughout the world are under immense pressure to improve outcomes for all students (Witziers, Bosker \& Kruger, 2003; Robinson, 2007; Hallinger, 2008; Marzano, Waters \& McNulty, 2005). Recent literature suggests this accountability may be warranted, at least in part, as there is overwhelming evidence that building principals can positively impact student achievement through effective behavior as instructional leaders (Cotton, 2003; Hattie, 2009; Marzano, Waters \& McNulty, 2005; Robinson, 2007). Several recent metaanalyses of research on instructional leadership identified the importance of principals using data to monitor student progress and the effectiveness of school practices (Cotton, 2003; Hattie, 2009; Marzano, Waters \& McNulty, 2005; Robinson, 2007). The problem 
is, little research exists that examines the relationship between the high school principal's monitoring student progress and student achievement.

\section{Significance of the Problem}

Research by Luo (2003) divides leadership into four domains or dimensions which include: (a) instructional leadership; (b) leadership in school vision; (c) school organization operation; and (d) collaborative partnership and larger-context politics. This study will focus on the ways principals use data in the instructional leadership dimension to monitor student progress. The pressure to use data in school improvement is emanating from federal, state and local sources.

As mentioned previously, the federal No Child Left Behind Act of 2002 has driven education at the state and local levels for the past decade. More recently, Race to the Top Grants have been issued to states by the U.S. Department of Education in order to drive changes in education that will lead to improved student outcomes. The climate at the state level reflects the pressure applied by the federal government. At the local level, school boards, superintendents and the more enlightened communities expect school principals to use data to identify how many of their students are currently achieving at the proficient level or above and determining what gaps exist between sub-groups and their counter-parts. Monitoring the effectiveness of initiatives aimed at improving student outcomes and student progress has been added to the traditional principal responsibilities of beans, balls and buses (Bernhardt, 2003).

\section{Population and Sampling}

The population for this study consisted of teachers in the 44 high schools located in Ohio's Region 12 during the 2010-2011 school year. Region 12 is a twelve-county 
region in southeastern Ohio that is one of 16 regions in Ohio's statewide system of support. A list of the high schools within the population is located in Appendix A. This list was obtained from the office of the Region 12 State Support Team which serves as the statewide system of support for the districts and schools comprising the population under study. The non-probability sample for this study consisted of 18 high schools within the region. The sample was vetted through three levels of self-selection. First, district superintendents had to agree to allow their high schools to participate by responding to a solicitation email. Second, high school principals also had to agree to participate and additionally, were asked to forward an email to teachers from the researcher requesting their participation in the study. Finally, teachers decided whether or not they would participate. The main limitation associated with this method of sampling is the possibility that schools agreeing to participate may not be representative of the population.

Participation consisted of clicking a link to the instrument hosted on the website, SurveyMonkey. There are 42 public school districts in Region 12, 19 of those initially indicated they would each allow their high school to participate. Just before data collection began however, one high school principal requested her school be excluded bringing the total number of high schools to 18 .

The sample of teachers from 18 high schools was divided into three groups of 6 according to their Performance Index scores from the 2010-11 state report card data. The schools were simply listed from the highest Performance Index to the lowest and divided evenly between Low, Medium and High Performance Index Groups. Analysis of Variance detected a statistically significant difference when comparing the three 
Performance Index categories $(\mathrm{F}=24.937 ; \mathrm{df}=2 ; \mathrm{p}<0.001)$. Bonferroni and Scheffe posthoc comparisons suggest significant differences between all three Performance Index categories.

The 18 schools that participated in the study employ an estimated 607 teachers and serve an estimated 10,670 students. Table 3.1 illustrates the response rate of the teachers by Performance Index group. It should be noted that 213 teachers from 18 high schools volunteered to participate in this study. This corresponds to a $35 \%$ participation rate from the sample of high school teachers.

Table 3.1

Respondents by PI Category

Performance

\begin{tabular}{|c|c|c|c|}
\hline Index & Teachers & Students & Respondents \\
\hline Low & 205 & 3424 & $95(46 \%)$ \\
\hline Medium & 214 & 3644 & $72(34 \%)$ \\
\hline High & 188 & 3602 & $46(25 \%)$ \\
\hline Totals & 607 & 10,670 & $213(35 \%)$ \\
\hline
\end{tabular}

\section{Instrumentation}

Teachers' perceptions' of their principal's monitoring student progress is the dependent variable in this study. It will be measured by high school teachers completing the Monitor Student Progress Subscale of the Principal Instructional Management Rating Scale (PIMRS) Teacher Form 2. In addition to the five items from the Monitor Student Progress subscale, eleven more items were added to the survey. These additional items were designed to gather data about teacher perceptions of standardized testing and 
will be addressed descriptively in Chapter Four. The proxy for student achievement, the independent variable, was the Performance Index for each high school listed on their Local Report Card (LRC) for the 2010-2011 school year. High schools were ranked according to this measure and placed into one of three groups denoting a low, medium or high level of student achievement. A system of ordering the high schools was devised and each high school was assigned a code to conceal actual school names. Table 3.2 shows the student achievement groups for this study using the coded high school names. Table 3.2

High Schools by Achievement Group

$\underline{\text { Low PI }} \quad \underline{\text { Medium PI }} \quad \underline{\text { High PI }}$

\begin{tabular}{cccccc}
$\begin{array}{c}\text { Coded } \\
\text { HS }\end{array}$ & $\begin{array}{c}\text { Performance } \\
\text { Index }\end{array}$ & $\begin{array}{c}\text { Coded } \\
\text { HS }\end{array}$ & $\begin{array}{c}\text { Performance } \\
\text { Index }\end{array}$ & $\begin{array}{c}\text { Coded } \\
\text { HS }\end{array}$ & $\begin{array}{c}\text { Performance } \\
\text { Index }\end{array}$ \\
\hline 25 & 96.5 & 32 & 99.4 & 4 & 104 \\
15 & 96.2 & 10 & 98.6 & 38 & 102.5 \\
32 & 95.8 & 12 & 98.5 & 5 & 102 \\
43 & 94.6 & 13 & 97.5 & 36 & 101.1 \\
23 & 92.6 & 26 & 97.5 & 22 & 100.6 \\
14 & 89.7 & 40 & 97.4 & 28 & 99.7 \\
M (SD) & $94.23(2.6)$ & M (SD) & $98.15(.812)$ & M (SD) & $101.6(1.5)$
\end{tabular}

In order to investigate the possibility that a relationship exists between the principals' monitoring of student progress and student achievement, an analysis of variance (ANOVA) was conducted on the PIMRS scores between and within the groups denoting the three levels of student achievement. 
Principal Instructional Management Rating Scale. The following questions make up the Monitor Student Progress Subscale. The stem to each question reads, "To what extent does your principal..."

1. Meet individually with teachers to discuss student progress

2. Discuss academic performance results with the faculty to identify curricular strengths and weaknesses

3. Use test and other performance measures to assess progress toward school goals

4. Inform teachers of the school's performance results in written form (e.g., in a memo or newsletter)

5. Inform students of school's academic progress.

Teachers were asked to respond to these items using a 5 point Likert-type scale with the following descriptors: almost never; seldom; sometimes; frequently; and almost always. The score from each teacher was placed within the appropriate Performance Index group according to their school's academic achievement; low, medium or high.

The Principal Management Instructional Rating Scale (PIMRS) was developed in response to a lack of research focused on what principals do to manage curriculum and instruction in schools (Hallinger, 1983). The PIMRS consists of 50 behaviorally anchored items (for more on behaviorally anchored items see Latham \& Wexley (1981)) divided into 10 subscales of five items each. Since the focus of this study is to examine the relationship between high school principals' monitoring student progress and student achievement, the Monitor Student Progress (MSP) subscale will be the only one utilized in this study. There are three parallel forms of the PIMRS: principal self-assessment 
form; teacher form; and, supervisor form. This study will utilize the teacher form because validation studies in the United States indicate that it provides the most valid data (Hallinger, 2011).

Ratings on the PIMRS do not demonstrate the success of a principal in a particular subscale but rather show active leadership in that area. Behaviorally anchored rating scales are statements of critical job-related behaviors that raters can use to assess an individual's performance within a given dimension of the job. It is not surprising, taking this into consideration, that data generated by the PIMRS is used most effectively to underscore patterns of principal leadership (Hallinger, 1982).

Internal consistency refers to the consistency with which all items of an instrument are measuring the same thing. Cronbach's alpha was used to measure reliability of the PIMRS and all subscales surpassed the .80 level. This would indicate that the PIMRS represents the instructional leadership of a school principal well (Krathwohl, 1998). Latham and Wexley (1981) state that .80 should be the minimum standard of reliability for a behaviorally anchored rating scale to be used for assessing personnel appraisal. For research purposes, .70 is acceptable. Hallinger's (1982) original analysis indicated that the MSP subscale had a reliability coefficient of .90. Cronbach's Alpha for the Monitor Student Progress subscale items on the survey used in this study was .88 .

In the original PIMRS administration, validity was tested by conducting an Analysis of Variance (ANOVA) of the within school groups and the between school groups. In order for an instrument to be valid, there must be more variance between schools than within schools. The $F$ value of the MSP subscale was 2.66 which indicated 
that the between school variance was greater than the within school variance with statistical significance at the .05 level (Hallinger, 1982). Additionally, Hallinger conducted construct validity analysis using conceptual-empirical linkage. School documents such as staff meeting agendas and minutes and principal newsletters showed strong documentary evidence that the perceptions collected by the PIMRS for MSP were accurate (Hallinger, 1982).

Perceptions of standardized testing survey items. Eleven items were added to the PIMRS that examined teachers' perceptions of standardized testing. Seven of these items investigated teacher attitudes towards student achievement tests and student achievement data. Teachers were asked to respond to a Likert-type scale from Strongly Disagree to Strongly Agree. The following items made up this section of the survey:

1. Results from student achievement data should drive our curriculum.

2. Results from student achievement data should drive our teachers' instruction.

3. Student achievement data helps me do my job better.

4. Preparing students for achievement testing can be a useful learning activity.

5. Standardized achievement tests get in the way of my work.

6. Results from achievement test scores help me plan instruction more effectively.

7. The Ohio Academic Content Standards define well what I believe students need to learn. 
The remaining four items measured teacher perceptions of the use of student achievement data in public education. In completing these items, teachers were asked to indicate the appropriateness of time spent on certain activities relating to the use of student achievement data. The following items were presented to teachers and they were asked to choose between

- not enough time is spent on this activity;

- just the right amount of time is spent on this activity; and

- too much time is spent on this activity.

The four items are listed below:

1. Amount of time teachers spend reviewing student achievement data.

2. Amount of time teachers spend preparing students for standardized tests such as the OGT.

3. Amount of time students spend taking standardized tests.

4. Amount of time school administrators spend reviewing student achievement data.

OGT - reading and math. The purpose of the Ohio Graduation Test is threefold; (1) to determine eligibility for a high school diploma, (2) to serve as a way of informing students, parents and teachers of progress in the knowledge, skills and abilities of $10^{\text {th }}$ grade students, and (3) the test can provide a way for schools to identify weaknesses in their curriculum, instruction, and assessment programs (Moore, 2008). Obviously with such high stakes resting on the outcome of the OGT, it is important that this assessment be valid and reliable. This study will use Krathwohl's (1998) definition 
of validity as an assessment measuring what it is supposed to measure and reliability as providing a consistent measurement over items, over tests and over time.

The validity of the Ohio Graduation Tests is based on what Cronbach (1988) references as validation by community. The problem with content or criterion-referenced tests is that there is no variable to predict. Both the content and the acceptable performances demonstrating mastery of that content come from the community so as a result, the community is expert in this scenario. What follows then is a description of how the content standards were developed, and then what process is used to develop tests that assess that content and how those tests are evaluated.

The process used to create the Ohio Graduation Tests utilizes stakeholders to a large degree. Committees are formed to create not only the tests, but also the standards, or criterion, upon which the tests are based. Creation of the content standards upon which the OGT is based began in 1997 with the formation of six writing teams representing the following content areas: (1) the arts; (2) English language arts; (3) foreign languages; (4) mathematics; (5) science; and (6) social studies (Moore, 2008).

An item appears on the OGT after first being written by an outside vendor. These items are developed with the purpose of assessing a particular benchmark in the content standards. The items are then reviewed by collaborative groups composed of many stakeholders, but consisting mainly of content area teachers. Table 3.3 provides the Math Content Advisory Committee for July, 2005 as an example. The representatives listed in Table 3.3 represent a diverse mix of urban and rural, large and small, and rich and poor schools and districts throughout Ohio. Note also the presence of higher education in this collaborative group. 
Once items are written and approved by the committees, a test blueprint is developed so that every operational form of each test is comparable to other operational forms including those used for the setting of performance standards. Setting the performance standards involve setting the ability levels required for a test performance to be considered proficient. The standards for reading and math were set in 2004 using the bookmark method of standard setting. For more information on this process, please refer to Moore (2008).

Table 3.3

Math Content Advisory Committee for 6 July 2005

\begin{tabular}{ll}
\hline Coshocton High School & Mansfield City Schools \\
Brush High School & Western High School \\
Science/Math Network & Tri-Village High School \\
Morgan Local Schools & Chippewa High School \\
Wright Patterson AFB & University of Rio Grande \\
Xenia High School & Ohio Northern University \\
Beachwood High School & Robert A. Taft High School \\
Columbus Public Schools & Preble County Educational Service Center \\
Champion Middle School & Auburn Career Center \\
Cleveland State University & Harding High School \\
Columbus State Community College & Reading Jr./Sr. High School \\
Toledo Public Schools & Willard High School
\end{tabular}


The OGT uses two types of test items, Selected Response (SR) and Constructed Response (CR) in all content areas. The constructed response items are read and scored by college educated and trained readers. Two readers review each response with a third reader being utilized if the scores of the first two readers are not adjacent. Consequently, a test that has six CR items will probably have been read by 12 or more readers resulting in each student's score coming from a community of readers (Moore, 2008).

Again, due to the lack of a variable to predict, the evidence of validity for the OGT is based on the fact that "both the content and suitable performance are synthesized from the community of educators and those with a stake in educational outcomes (no matter how varied and unquantifiable those outcomes might be); the community is expert" (Moore, 2008. p. 8).

Data from the 2006 spring administration is presented in Table 3.4 with the respective Cronbach alpha statistics.

Table 3.4

Cronbach Alpha Statistics for the Spring 2006 OGT

$\begin{array}{ll}\text { Content Area } & \text { Test Reliability } \\ \text { Reading } & .829 \\ \text { Mathematics } & .886\end{array}$

These numbers, in addition to the previous information on validity, lead this researcher to concur with Moore (2008) that "The Ohio Graduation Tests are suitable for making valid inferences about what $10^{\text {th }}$ grade students know and can do in the context of Ohio's Academic Content Standards" (p. 42). 
Performance Index. Student performance in all subject areas of the Ohio Achievement Assessment (OAA) and Ohio Graduation Test (OGT) is given one of five ratings depending on the scaled score of the student: Limited; Basic; Proficient;

Accelerated; or Advanced. Students' raw scores are converted into scaled scores which are consistent across OGT test forms. Table 3.5 provides a listing of the score ranges for all subjects and all performance levels of the 2010 Ohio Graduation Test (ODE, 2010).

Table 3.5

Score ranges for all subjects and all performance levels

\begin{tabular}{llcc}
\multicolumn{1}{c}{ Subject } & Performance Level & Raw Score & Scaled Score \\
\hline \multirow{4}{*}{ Reading } & Advanced & $39.5-48.0$ & $448-545$ \\
& Accelerated & $32.5-39.0$ & $429-447$ \\
& Proficient & $20.0-32.0$ & $400-428$ \\
& Basic & $13.5-19.5$ & $383-399$ \\
& Limited & $0.0-13.0$ & $260-382$ \\
\hline \multirow{4}{*}{ Mathematics } & Advanced & $36.0-46.0$ & $444-557$ \\
& Accelerated & $30.0-35.5$ & $425-443$ \\
& Proficient & $20.5-29.5$ & $400-424$ \\
& Basic & $15.0-20.0$ & $384-399$ \\
Writing & Limited & $0.0-14.5$ & $252-383$ \\
\hline \multirow{5}{*}{ Social Studies } & Advanced & $42.5-48.0$ & $476-573$ \\
& Accelerated & $35.0-42.0$ & $430-475$ \\
& Proficient & $26.5-34.5$ & $400-429$ \\
& Basic & $18.5-26.0$ & $378-399$ \\
& Limited & $0.0-18.0$ & $267-377$ \\
\hline & Advanced & $37.5-48.0$ & $445-609$ \\
& Accelerated & $31.5-37.0$ & $425-444$ \\
& Proficient & $22.5-31.0$ & $400-424$ \\
& Basic & $13.5-22.0$ & $371-399$ \\
& Basic & $0.0-13.0$ & $215-370$ \\
\hline \multirow{5}{*}{ Limited } & Limited & $37.0-48.0$ & $446-581$ \\
& Advanced & $23.0-32.0$ & $429-445$ \\
& & $16.5-22.5$ & $400-428$ \\
& & $0.0-16.0$ & $382-399$ \\
& & & $227-381$ \\
\hline
\end{tabular}


The Performance Index (PI) is a calculation that measures OGT test performance based on the numbers of students at each performance level. Scores for the PI are calculated by assigning a weighted score to each performance level as follows (ODE, 2007):

- Untested students - 0 points;

- Limited - 0.3 points;

- Basic - 0.6 points;

- Proficient - 1.0 points;

- Accelerated - 1.1 points; and

- Advanced - 1.2 points.

The percentage of students at each performance level is multiplied by their respective weight, and the totals for each performance level are summed to get the building's overall Performance Index score. An example of how this might look is provided in Table 3.6.

Table 3.6

Example Performance Index Calculation

\begin{tabular}{lccc}
\multicolumn{1}{c}{ Performance Level } & \% of Students at Level & Weight & Score \\
\hline Untested & 5 & 0.0 & 0 \\
Limited & 20 & 0.3 & 6.0 \\
Basic & 25 & 0.6 & 15.0 \\
Proficient & 35 & 1.0 & 35.0 \\
Accelerated & 5 & 1.1 & 5.5 \\
Advanced & 10 & 1.2 & 12.0 \\
& & Performance Index Score: & 73.5 \\
\hline
\end{tabular}

The percentage of students at each level equals the number of tests at each performance level divided by the total number of tests multiplied by 100 (ODE, 2007). 
Performance Index will be an important measure in this proposed study for two reasons: (1) it includes all five subject areas of the OGT rather than only reading or math, and (2) it indicates school effectiveness by reflecting a school's percentage of students at the higher levels. A school with all of its students achieving at the Advanced level on all tests would have a PI of $120,100 \%$ multiplied by 1.2 . The implication is that the higher

the PI, the larger the greater the number of students a school has scoring in the proficient or above range.

\section{Data Collection}

The following steps provide an explanation of how high school teachers' perceptions of their principals' monitoring progress behavior were collected:

1. In the beginning of August, a letter of solicitation (see Appendix C) was sent to each superintendent in Region 12 requesting that his or her district participate in the study. This letter and all subsequent communication were in compliance with the requirements of West Virginia University's Internal Review Board (IRB). A follow-up reminder was sent to Superintendent's that had not responded by the middle of August.

2. Superintendents that agree to participate received a formal letter of consent (Appendix D) to be signed and returned.

3. The individual high school principals of the participating districts were contacted by email with the Principal's Letter of Participation (Appendix E). This letter contained much of the same information as the superintendent's first letter providing the details of the study. Two 
additional reminder emails were sent to the high school principals throughout September.

4. Teachers were contacted by the researcher with an email forwarded through their building principal and provided a Letter of Informed Consent (Appendix F).

5. Participating teachers accessed the PIMRS (Appendix G) via a URL provided by an email forwarded to staff through the building principal. There were three identical forms of the PIMRS denoted as Forms A, B and C. Teachers from low achieving schools completed Form A, teachers from medium achieving schools completed Form B and teachers from high achieving schools completed Form C. There was absolutely no way to identify teacher responses with specific high schools. Teacher responses were identifiable only to the student achievement group of which their high school is a member (high, medium or low). This alleviated teacher concerns about completing a survey forwarded from their supervisor.

The URL link to the Survey Monkey page containing the PIMRS Monitoring Student Progress subscale contained a brief section requesting certain demographic information from the teacher completing it. The demographic section asked for the following information:

1. Years, at the end of this school year, that the respondent has worked with the current principal; and

2. Years of experience as a teacher at the end of this school year. 


\section{Data Analysis}

Completed surveys were accessed via Survey Monkey. The research question affiliated with the survey and its corresponding null hypotheses are listed below. Accompanying the research question is the statistical method used to answer it.

RQ1: Is there a relationship between teacher's perceptions of high school principals' monitoring student progress and student achievement as measured by the Performance Index according to Ohio's local report card data?

$\mathrm{H}_{0} 1$ : There is no relationship between teacher's perceptions of high school principals' monitoring student progress as measured by the Performance Index score on the school's Ohio Local Report Card data.

RQ2: RQ2 - Is there a relationship between teacher perceptions of standardized testing and student achievement as measured by the Performance Index on Ohio's local report card data?

The first research question examined the relationship between teacher's perceptions of high school principal's instructional leadership behavior in the domain of Monitoring Student Progress and student achievement. ANOVA was used to examine this relationship by measuring the variance within and between three groups of schools. The groups were determined by rating each school according to the Performance Index from the 2010-2011 school year. As the rating scale data was collected from the teachers, results will be entered into the appropriate group according to where the school ranked on each measure. The variance was then examined within each group and between each group. 
The second research question examined teachers' attitudes towards student achievement tests and student achievement data, and teachers perceptions of the amount of time spent on the appropriateness of time spent on certain student achievement related activities. This research question was not part of the original proposed study and therefore will not be examined through null hypothesis testing. This research question will be addressed descriptively in the following chapters.

\section{Guarantee of Anonymity and Confidentiality}

As per requirements of West Virginia University's Doctor of Education in Educational Leadership Studies, the researcher completed the Collaborative Institutional Training Initiative's Human Research Curriculum. Topics included issues regarding risk, consent, and confidentiality when conducting research with human subjects. This informed my approach in conducting this study.

Anonymity of all participants was assured and explained on the rating scale that was distributed through Survey Monkey. All data was secured on the password protected site. There was absolutely no personally identifiable information or any information that would allow the researcher or anyone else to connect teacher responses to the specific school in which they are employed. Email tracking was disabled on the PIMRS survey. Teacher responses were identified only with the category in which their school falls, e.g. high, medium or low.

\section{Summary}

This chapter explained all aspects of the methods that will be used in this proposed study. The purpose of the study was to examine the relationship between the instructional leadership behavior of high school building principals in the domain of 
Monitoring Student Progress and student achievement. The proxy for student achievement was the Performance Index of each school as reported on Ohio's Local Report Card for the 2010-2011 school year. Teachers' perceptions' of their principal's instructional leadership behavior of Monitoring Student Progress was assessed by administering the Monitoring Student Progress subscale of the Principal Instructional Management Rating Scale. The population consisted of teachers from 44 high schools in Ohio's Region 12. The sample consisted of teachers in 18 high schools where the superintendent and principal agreed to participate.

A one-way ANOVA was conducted to determine if there is a significant relationship between monitoring student progress and student achievement. The sample was divided into three groups of 6 schools each: low, medium and high Performance Index. An analysis of the variance (ANOVA) within the groups and between the groups was used to determine the existence of a relationship between the two variables. 


\section{Chapter Four: Results}

This chapter begins with a description of the participating schools and teachers followed by a description of the Monitoring Student Progress survey results. The third section of this chapter will descriptively address 11 additional survey items that measured teacher perceptions relating to standardized testing. The chapter concludes with a brief summary.

The purpose of this study was to examine the relationship between principals' monitoring student progress, as perceived by teachers, and student achievement in southeastern Ohio. The study was guided by the following research question and the respective null hypothesis:

RQ1: Is there a relationship between teacher's perceptions of high school principals' monitoring student progress and student achievement as measured by the Performance Index according to Ohio's local report card data?

$\mathrm{H}_{0} 1$ : There is no relationship between teacher's perceptions of high school principal's monitoring student progress as measured by the Performance Index according to Ohio's local report card data?

RQ2 - Is there a relationship between teacher perceptions of standardized testing and student achievement as measured by the Performance Index on Ohio's local report card data?

The research questions above were addressed through an analysis of responses gathered from the Monitor Student Progress (MSP) subscale of the Principal Instructional Management Rating Scale (PIMRS) (Hallinger, 1982) and 11 items developed by the researcher. The following questions make up the Monitor Student 
Progress Subscale, the stem to each question reads, "To what extent does your principal..."

1. Meet individually with teachers to discuss student progress;

2. Discuss academic performance results with the faculty to identify curricular strengths and weaknesses;

3. Use test and other performance measures to assess progress toward school goals;

4. Inform teachers of the school's performance results in written form (e.g., in a memo or newsletter); and

5. Inform students of school's academic progress.

Teachers are asked to respond to these items using a Likert-type scale from 1 - Almost Always, to 5 - Almost Never.

Eleven items were added to the PIMRS that examined teachers' perceptions of standardized testing. Seven of these items investigated teacher attitudes towards student achievement tests and student achievement data. Teachers were asked to respond to a Likert-type scale from Strongly Disagree to Strongly Agree. The following items made up this section of the survey:

1. Results from student achievement data should drive our curriculum.

2. Results from student achievement data should drive our teachers' instruction.

3. Student achievement data helps me do my job better.

4. Preparing students for achievement testing can be a useful learning activity. 
5. Standardized achievement tests get in the way of my work.

6. Results from achievement test scores help me plan instruction more effectively.

7. The Ohio Academic Content Standards define well what I believe students need to learn.

The remaining four items measured teacher perceptions of the use of student achievement data in public education. In completing these items, teachers were asked to indicate the appropriateness of time spent on certain activities relating to the use of student achievement data. The following items were presented to teachers and they were asked to choose between

- not enough time is spent on this activity;

- just the right amount of time is spent on this activity; and

- $\quad$ too much time is spent on this activity.

The four items are listed below:

1. Amount of time teachers spend reviewing student achievement data.

2. Amount of time teachers spend preparing students for standardized tests such as the OGT.

3. Amount of time students spend taking standardized tests.

4. Amount of time school administrators spend reviewing student achievement data. 


\section{Description of Sample}

The dependent variable in this study was teacher perceptions of their principal's monitoring student progress behavior. Since the Monitoring Student Progress subscale of the PIMRS Teacher Form (Hallinger, 1982) was used to measure the dependent variable, it was necessary to reach out to teachers for survey completion. This required three sets of permissions. First, district superintendents had to agree to allow their high schools to participate by responding to a solicitation email. Second, high school principals also had to agree to participate and additionally, were asked to forward an email to teachers from the researcher requesting their participation in the study. Finally, teachers decided whether or not they would participate. Participation consisted of clicking a link to the instrument hosted on the website, SurveyMonkey. There are 42 public school districts in Region 12, 19 of those initially indicated they would each allow their high school to participate. Just before data collection began however, one high school principal requested her school be excluded bringing the total number of high schools to 18 .

The sample of 18 high schools was divided into three groups of six according to their Performance Index scores from the 2010-11 state report card data. The schools were simply listed from the highest Performance Index to the lowest and divided evenly between Low, Medium and High Performance Index Groups. Analysis of Variance detected a statistically significant difference when comparing the three Performance Index categories $(\mathrm{F}=24.937 ; \mathrm{df}=2 ; \mathrm{p}<0.001)$. Bonferroni and Scheffe post-hoc comparisons showed significant differences between all three Performance Index categories. A system of ordering the high schools was devised and each high school was 
assigned a code to conceal actual school names. Table 4.1 shows the student

achievement groups for this study using the coded high school names.

Table 4.1

High Schools by Achievement Group

$\underline{\text { Low PI }} \quad \underline{\text { Medium PI }} \quad \underline{\text { High PI }}$

\begin{tabular}{cccccc}
$\begin{array}{c}\text { Coded } \\
\text { HS }\end{array}$ & $\begin{array}{c}\text { Performance } \\
\text { Index }\end{array}$ & $\begin{array}{c}\text { Coded } \\
\text { HS }\end{array}$ & $\begin{array}{c}\text { Performance } \\
\text { Index }\end{array}$ & $\begin{array}{c}\text { Coded } \\
\text { HS }\end{array}$ & $\begin{array}{c}\text { Performance } \\
\text { Index }\end{array}$ \\
\hline 25 & 96.5 & 32 & 99.4 & 4 & 104 \\
15 & 96.2 & 10 & 98.6 & 38 & 102.5 \\
32 & 95.8 & 12 & 98.5 & 5 & 102 \\
43 & 94.6 & 13 & 97.5 & 36 & 101.1 \\
23 & 92.6 & 26 & 97.5 & 22 & 100.6 \\
14 & 89.7 & 40 & 97.4 & 28 & 99.7 \\
M (SD) & $94.23(2.6)$ & M (SD) & $98.15(.812)$ & M (SD) & $101.6(1.5)$
\end{tabular}

The 18 schools that participated in the study employ an estimated 607 teachers and serve an estimated 10,670 students. Table 4.2 illustrates the response rate of the teachers by Performance Index group. It should be noted that 213 teachers from 18 high schools volunteered to participate in this study. This corresponds to a $35 \%$ participation rate from the sample of high school teachers. 
Table 4.2

Respondents by PI Category

\begin{tabular}{|c|c|c|c|}
\hline $\begin{array}{l}\text { Performance } \\
\text { Index }\end{array}$ & Teachers & Students & Respondents \\
\hline Low & 205 & 3424 & $95(46 \%)$ \\
\hline Medium & 214 & 3644 & $72(34 \%)$ \\
\hline High & 188 & 3602 & $46(25 \%)$ \\
\hline Totals & 607 & 10,670 & $213(35 \%)$ \\
\hline
\end{tabular}

The survey consisted of 16 items. The first survey item asked teachers how many years they would have worked with the current principal at the end of the $2011-2012$ school year. Table 4.3 illustrates their responses by Performance Index group.

Table 4.3

Teaching Experience with Current Principal

\begin{tabular}{cccc} 
& Low PI & $\begin{array}{c}\text { Medium } \\
\text { PI }\end{array}$ & High PI \\
\cline { 2 - 4 } 1 & 8 & 5 & 1 \\
2 to 4 & 63 & 23 & 23 \\
5 to 9 & 16 & 21 & 9 \\
10 to 15 & 4 & 16 & 7 \\
More than 15 & 3 & 7 & 5 \\
Left Blank & 1 & 0 & 0
\end{tabular}

Note. The number of Years working with the principal at the end of the 2011 - 2012 school-year. 
The second survey item asked teachers how many total years of experience they will have had as a full-time teacher at the end of the 2011 - 2012 school year. Table 4.4 illustrates their responses.

Table 4.4

Teaching Experience

\begin{tabular}{cccc} 
& Low PI & $\begin{array}{c}\text { Medium } \\
\text { PI }\end{array}$ & High PI \\
\cline { 2 - 4 } 1 & 5 & 2 & 1 \\
2 to 4 & 9 & 4 & 7 \\
5 to 9 & 9 & 11 & 4 \\
10 to 15 & 14 & 19 & 11 \\
More than 15 & 58 & 36 & 23
\end{tabular}

Note. Number of years teaching at any school at the end of the 2011-2012 school year.

\section{Summary of Monitoring Student Progress Results}

This section of the study provides a summary of the results. Teachers were asked to respond to five questions rating the degree to which their building principal engaged in certain behaviors. The research question asks, "Is there a relationship between teacher perceptions of high school principals monitoring student progress and student achievement as measured by the Performance Index score on Ohio's local report card data?" In order to answer the research question, descriptive statistics such as means $(M)$ and standard deviations $(S D)$ for teacher responses were calculated for each of the 5 items of the Monitoring Student Progress (MSP) subscale of the Principal Instructional Management Rating Scale (PIMRS). These statistics are reported in Table 12. 
Table 4.5

PIMRS Teacher Response Means

Low PI

\begin{tabular}{|c|c|c|c|c|}
\hline Q1 & Q2 & Q3 & Q4 & Q5 \\
\hline 3.08 & 3.61 & 3.86 & 3.84 & 3.31 \\
\hline 1.11 & 0.92 & 0.87 & 1.04 & 1.18 \\
\hline
\end{tabular}

Medium PI

$\begin{array}{llllll}\text { Group } M & 3.28 & 4.04 & 4.34 & 4.35 & 3.84 \\ \text { Group } S D & 1.26 & 0.95 & 0.86 & 0.96 & 1.15\end{array}$

High PI

\begin{tabular}{llllll} 
Group $M$ & 3.09 & 3.81 & 4.33 & 4.26 & 3.95 \\
Group $S D$ & .87 & 1.03 & 0.92 & 1.11 & 0.82 \\
\hline
\end{tabular}

Meet individually with teachers to discuss student progress. Item 1 of the

survey asked teachers, "To what extent does your principal meet individually with teachers to discuss student progress?" Table 4.6 show that Analysis of Variance detected no statistically significant difference when comparing mean responses to this item across the three Performance Index categories $(F=0.694 ; \mathrm{df}=2, \mathrm{p}=0.501)$.

Table 4.6

ANOVA Item 1 from PIMRS

$\begin{array}{lccccr} & \begin{array}{c}\text { Sum of } \\ \text { Squares }\end{array} & \text { Df } & \begin{array}{c}\text { Mean } \\ \text { Square }\end{array} & \text { F } & \text { Sig } \\ \text { Between Groups } & 1.731 & 2 & .866 & .694 & .501 \\ \text { Within Groups } & 245.769 & 197 & 1.248 & \end{array}$

Total

247.500

199 


\section{Discuss academic performance results with faculty to identify curricular}

strengths. The second item of the survey asked teachers, "To what extent does your principal discuss academic performance results with faculty to identify curricular strengths?" Analysis of Variance detected a statistically significant difference when comparing responses to this item across the three Performance Index categories $(\mathrm{F}=3.911 ; \mathrm{df}=2 ; \mathrm{p}<0.023)$. Bonferroni and Scheffe post-hoc comparisons indicate the significance to be based on the difference between the Low performing group and the Medium performing group.

Table 4.7

ANOVA Item 2 PIMRS

\begin{tabular}{|c|c|c|c|c|c|}
\hline & $\begin{array}{l}\text { Sum of } \\
\text { Squares }\end{array}$ & Df & $\begin{array}{l}\text { Mean } \\
\text { Square }\end{array}$ & $\mathrm{F}$ & Sig \\
\hline Between Groups & 7.114 & 2 & 3.557 & 3.911 & .022 \\
\hline Within Groups & 178.243 & 196 & .909 & & \\
\hline Total & 185.357 & 198 & & & \\
\hline
\end{tabular}

Use tests and other performance measures to assess progress toward school goals. Item 3 of the survey asked teachers, "To what extent does your principal use tests and other performance measures to assess progress toward school goals?" Analysis of Variance detected a statistically significant difference when comparing responses to this item across the three Performance Index categories $(F=7.030 ; \mathrm{df}=2 ; \mathrm{p}<0.002)$.

Bonferroni and Scheffe post-hoc comparisons showed the significance to be based on the differences between the Low performing group and the Medium and High performing 
groups. No significant difference was detected between the Medium and High

performing groups.

Table 4.8

ANOVA Item 3 PIMRS

\begin{tabular}{|c|c|c|c|c|c|}
\hline & $\begin{array}{l}\text { Sum of } \\
\text { Squares }\end{array}$ & Df & $\begin{array}{c}\text { Mean } \\
\text { Square }\end{array}$ & $\mathrm{F}$ & Sig \\
\hline Between Groups & 10.833 & 2 & 5.417 & 7.030 & .001 \\
\hline Within Groups & 151.026 & 196 & .771 & & \\
\hline Total & 161.859 & 198 & & & \\
\hline
\end{tabular}

Inform teachers of the school's performance results in written form. The fourth item of the survey asked teachers, "To what extent does your principal inform teachers of the school's performance results in written form?" Analysis of Variance detected a statistically significant difference when comparing responses to this item across the three Performance Index categories $(\mathrm{F}=5.335 ; \mathrm{df}=2 ; \mathrm{p}<0.007)$. Bonferroni and Scheffe post-hoc comparisons indicated the significance to be based on the difference between the Low performing group and the Medium performing group. 
Table 4.9

ANOVA Item 4 PIMRS

\begin{tabular}{|c|c|c|c|c|c|}
\hline & $\begin{array}{l}\text { Sum of } \\
\text { Squares }\end{array}$ & Df & $\begin{array}{l}\text { Mean } \\
\text { Square }\end{array}$ & $\mathrm{F}$ & Sig \\
\hline Between Groups & 11.296 & 2 & 5.648 & 5.335 & .006 \\
\hline Within Groups & 207.488 & 196 & 1.059 & & \\
\hline Total & 218.784 & 198 & & & \\
\hline
\end{tabular}

Inform students of the school's academic progress. Item 5 of the survey asked teachers, "To what extent does your principal inform students of the school's academic progress?" Analysis of Variance detected a statistically significant difference when comparing responses to this item across the three Performance Index categories $(F=7.030 ; \mathrm{df}=2 ; \mathrm{p}<0.002)$. Bonferroni and Scheffe post-hoc comparisons showed the significance to be based on the differences between the Low performing group and the Medium and High performing groups. No significant difference was detected between the Medium and High performing groups.

Table 4.10

ANOVA Item 5 PIMRS

\begin{tabular}{|c|c|c|c|c|c|}
\hline & $\begin{array}{l}\text { Sum of } \\
\text { Squares }\end{array}$ & Df & $\begin{array}{c}\text { Mean } \\
\text { Square } \\
\end{array}$ & $\mathrm{F}$ & Sig \\
\hline Between Groups & 16.338 & 2 & 8.169 & 6.700 & .002 \\
\hline Within Groups & 237.748 & 195 & 1.219 & & \\
\hline Total & 254.086 & 197 & & & \\
\hline
\end{tabular}


In summary, Analysis of Variance detected a statistically significant difference in four of the five items when comparing responses across the three Performance Index categories. See Table 4.10 for a list of the items, whether they are significant and the corresponding $\mathrm{p}$ value.

Table 4.11

Significant Differences Comparison

\begin{tabular}{lcc}
\multicolumn{1}{c}{ PIMRS Item } & $\begin{array}{l}\text { Significant } \\
\text { Difference? }\end{array}$ & p Value \\
\hline $\begin{array}{l}\text { To what extent does your principal... } \\
\begin{array}{l}\text { Meet individually with teachers to discuss student } \\
\text { progress? }\end{array}\end{array}$ & No & .501 \\
$\begin{array}{l}\text { Discuss academic performance results with faculty } \\
\text { to identify curricular strengths and weaknesses? }\end{array}$ & Yes & .022 \\
$\begin{array}{l}\text { Use tests and other performance measures to assess } \\
\text { progress toward school goals? }\end{array}$ & Yes & .001 \\
$\begin{array}{l}\text { Inform teachers of the school's performance results } \\
\text { in written form. }\end{array}$ & Yes \\
\begin{tabular}{l} 
Inform students of the school's academic progress \\
\hline
\end{tabular} & Yes & .006 \\
\hline
\end{tabular}

\section{Hypothesis and Null Hypothesis}

The hypothesis for this study was, "Is there a relationship between teacher's perceptions of high school principals' monitoring student progress and student achievement as measured by the Performance Index according to Ohio's local report card data?" The hypothesis was supported by rejecting the respective null hypothesis that “There is no relationship between teacher's perceptions of high school principal's monitoring student progress as measured by the Performance Index according to Ohio's 
local report card data?" The null hypothesis was rejected for the overall total of the five items and was rejected with four of the five survey items.

\section{Summary of Teacher Perceptions of Standardized Testing}

This section of the study provides a summary of the 11items measuring teacher perceptions of standardized testing. The research question asks, "Is there a relationship between teacher perceptions of standardized testing and student achievement as measured by the Performance Index on Ohio's local report card data?" In order to answer the research question, descriptive statistics such as means $(M)$ and standard deviations $(S D)$ for teacher responses were calculated for each of the 11 items. These statistics are reported in Table 4.12 .

These items were not part of the null hypothesis testing. Therefore, the results are discussed here for descriptive purposes and are not intended to be inferential. There were 11 items addressing teacher perceptions of standardized testing. The first seven items asked teachers to rate their agreement to various statements about standardized testing. The second four items asked teacher to make judgments about the amount of time educators spend in various activities relating to standardized testing.

Teachers' perceptions of standardized testing. Seven of these items investigated teacher attitudes towards student achievement tests and student achievement data. Table 4.12 descriptively summarizes the results of these items. 
Table 4.12

Teacher Perceptions of Standardized Testing

\begin{tabular}{|c|c|c|c|c|c|c|}
\hline Low PI & Q1 & Q2 & Q3 & Q4 & Q5 & Q6 \\
\hline Group $M$ & 3.7 & 3.8 & 3.7 & 3.5 & 3.4 & 3.4 \\
\hline Group $S D$ & .82 & .82 & .98 & .99 & .99 & .96 \\
\hline
\end{tabular}

Medium PI

$\begin{array}{llllllll}\text { Group } M & 3.5 & 3.6 & 3.6 & 3.4 & 3.4 & 3.4 & 3.2 \\ \text { Group } S D & .99 & 1.0 & 1.1 & .94 & 1.0 & 1.0 & 1.1\end{array}$

High PI

\begin{tabular}{llllllll} 
Group $M$ & 3.9 & 4.0 & 3.7 & 3.4 & 3.2 & 3.5 & 3.3 \\
Group $S D$ & .74 & .85 & .97 & .99 & 1.2 & .92 & .95 \\
\hline
\end{tabular}

Even though these questions were not the focus of this study, it should be noted that there were not statistically significant differences between Performance Index categories in regard to teachers' perceptions of standardized testing.

Time spent on standardized testing. In order to measure beliefs about the amount of time educators devote to standardized testing, teachers were asked to respond to four items. The results displayed in Table 4.13 may be interpreted as

1. 1 - Not enough time is spent on this activity.

2. 2 - Just the right amount of time is spent on this activity.

3. 3 - Too much time is spent on this activity. 
Teacher Perceptions of Time Spent on Standardized Testing

Low PI

\begin{tabular}{|c|c|c|c|}
\hline Q1 & Q2 & Q3 & $\mathrm{Q} 4$ \\
\hline 1.9 & 2.3 & 2.3 & 2.1 \\
\hline .76 & .63 & .63 & .66 \\
\hline
\end{tabular}

Medium PI

$\begin{array}{lllll}\text { Group } M & 2.0 & 2.5 & 2.5 & 2.2 \\ \text { Group } S D & .65 & .53 & .50 & .53\end{array}$

High PI

\begin{tabular}{lllll} 
Group $M$ & 2.0 & 2.5 & 2.5 & 2.2 \\
Group $S D$ & .56 & .50 & .50 & .46 \\
\hline
\end{tabular}

Even though these questions were not the focus of this study, it should be noted that there were not statistically significant differences between Performance Index categories in regard to teachers' perceptions of time spent on standardized testing.

\section{Summary of Results}

The results of the Monitoring Student Progress subscale of the PIMRS suggested that there were significant differences in teacher perceptions of their principals' monitoring student progress between the performance index categories on items two through five of the Monitoring Student Progress subscale of the PIMRS. Post-hoc comparisons suggest the significance to be based on the difference between the Low performing group and the Medium performing group on item two (discuss academic performance results with faculty to identify curricular strengths) and item four (inform teachers of the school's performance results in written form). Post-hoc comparisons suggest the significance of item three (use tests and other performance measures to assess progress toward school goals) and item five (inform students of the school's academic 
progress) to be based on the differences between the Low performing group and the Medium and High performing groups. No significant differences were found between the Medium and High Performance Index groups on any item.

Of the seven survey items measuring teacher attitudes toward standardized testing, there were differences found in the means of the responses although none were statistically significant. The same is true for the four survey items measuring teacher perceptions of time spent on standardized testing.

In this chapter, the researcher discussed the results of this study that examined the relationship between teachers' perceptions of their principals' monitoring student progress and student achievement. The results of this study were multi-faceted. On the one hand, certain aspects played out as one might expect; on the other hand, there were a few interesting surprises that will be discussed in Chapter Five. 


\section{Chapter Five: Discussion and Implications}

This study examined the relationship between teachers' perceptions of principals' monitoring student progress and student achievement. For purposes of the statewide system of support, Ohio is divided into 16 regions of varying geographical size and student population. Region 12 serves 42 school districts spread throughout twelve counties.

The study was guided by the following research question and the respective null hypothesis:

RQ1: Is there a relationship between teachers' perceptions of high school principals monitoring student progress and student achievement as measured by the Performance Index according to Ohio's local report card data?

$\mathrm{H}_{0} 1$ : There is no relationship between teachers' perceptions of high school principals monitoring student progress as measured by the Performance Index according to Ohio's local report card data?

RQ2: Is there a relationship between teacher perceptions of standardized testing and student achievement as measured by the Performance Index on Ohio's local report card data?

Teachers from eighteen high schools in Ohio's Region 12 participated in this study. The schools were divided into three student achievement groups by Performance Index on their 2011 Local Report Card; creating low, medium and high Performance Index groups with six high schools each. A total of 213 high school teachers participated in this study by rating their principal on the Monitor Student Progress subscale of the Principal Instructional Management Rating Scale (1983). 
The following questions make up the Monitor Student Progress Subscale, the stem to each question reads, "To what extent does your principal..."

1. Meet individually with teachers to discuss student progress;

2. Discuss academic performance results with the faculty to identify curricular strengths and weaknesses;

3. Use test and other performance measures to assess progress toward school goals;

4. Inform teachers of the school's performance results in written form (e.g., in a memo or newsletter); and

5. Inform students of school's academic progress.

Teachers were asked to respond to these items using a 5 point Likert-type scale with the following descriptors: almost never; seldom; sometimes; frequently; and almost always. Results from the completed surveys were analyzed using a one-way Analysis of Variance on the three Performance Index groups and through the use of descriptive statistics.

Eleven items were added to the PIMRS that examined teachers' perceptions of standardized testing. Seven of these items investigated teacher attitudes towards student achievement tests and student achievement data. Teachers were asked to respond to a Likert-type scale from Strongly Disagree to Strongly Agree. The following items made up this section of the survey:

1. Results from student achievement data should drive our curriculum.

2. Results from student achievement data should drive our teachers' instruction. 
3. Student achievement data helps me do my job better.

4. Preparing students for achievement testing can be a useful learning activity.

5. Standardized achievement tests get in the way of my work.

6. Results from achievement test scores help me plan instruction more effectively.

7. The Ohio Academic Content Standards define well what I believe students need to learn.

The remaining four items measured teacher perceptions of the use of student achievement data in public education. In completing these items, teachers were asked to indicate the appropriateness of time spent on certain activities relating to the use of student achievement data. The following items were presented to teachers and they were asked to choose between

- not enough time is spent on this activity;

- just the right amount of time is spent on this activity; and

- too much time is spent on this activity.

The four items are listed below:

1. Amount of time teachers spend reviewing student achievement data.

2. Amount of time teachers spend preparing students for standardized tests such as the OGT.

3. Amount of time students spend taking standardized tests.

4. Amount of time school administrators spend reviewing student achievement data. 


\section{Limitations}

There are four limitations associated with this study. First, a possible bias exists as the researcher was an employee of the Region 12 State Support Team for three years prior to the execution of the study. As such the researcher is known by many of the superintendents and principals throughout the region. This led to the second limitation that the researcher's previous role with the State Support Team possibly affected the selfselection of the participating districts. For instance, the three districts that the researcher worked most closely with all agreed to participate in the study. Of the remaining districts, six had worked with the Region 12 State Support Team either on a mandated or voluntary basis. The concern was that the high schools participating in the study would not be representative of the population. This concern did not manifest as there was an even distribution of Performance Index scores across the three groups.

A third limitation is that data will reflect student achievement from 2010-2011. As such it will provide only a snapshot of student performance at each school rather than a look at student achievement over a span of time. Fourth, the results of the Principal Instructional Management Rating Scale (PIMRS) will be based on teacher perceptions. This is the most reliable form of the PIMRS but there are some inherent biases in using teacher perceptions to report principal behavior.

\section{Discussion}

This section is divided into two parts. The first section begins by discussing each of the five items of the Monitor Student Progress Subcale of the Principal Instructional Management Rating Scale. The second section discusses the items relating to the teachers' perceptions of standardized testing and student achievement data use. 


\section{Monitor Student Progress Subscale of the Principal Instructional}

Management Rating Scale. For each item, descriptive statistics and the results of oneway ANOVA and post-hoc tests are presented along with literature germane to the findings. This section will conclude with a discussion of observations across the five items. Mean responses are given for each Performance Index group and for the total respondents on each item. The reader can interpret the findings by making the following associations (Lyons, 2010):

- 1 equals "Almost Never";

- 2 equals "Seldom";

- 3 equals "Sometimes";

- 4 equals "Frequently; and

- 5 equals "Almost Always".

Meet individually with teachers to discuss student progress. This item of the PIMRS (1983) asked individual teachers, "To what extent does your building principal meet individually with teachers to discuss student progress?" Analysis of Variance detected no statistically significant difference when comparing mean responses on this item $(\mathrm{F}=0.694 ; \mathrm{df}=2 ; \mathrm{p}=0.501)$. The mean response across the three Performance Index groups was 3.15. Table 5.1 provides information on each of the three Performance Index groups. 
Table 5.1

Meet Individually with Teachers to Discuss Student Progress

\begin{tabular}{ccccc} 
& Low & Medium & High & Total \\
\cline { 2 - 5 } $\mathrm{N}$ & 89 & 68 & 43 & 200 \\
Mean & 3.08 & 3.28 & 3.09 & 3.15 \\
$\mathrm{SD}$ & 1.11 & 1.26 & .87 & 1.12 \\
\hline
\end{tabular}

In comparison to the other items, teachers perceived their principals to engage in this behavior less than the four other behaviors contained in the survey. Teachers in each of the Performance Index groups rated their principals lowest on this item.

In a study by The Education Trust (2005), researchers compared practices of high impact and low impact high schools. All schools in the study had access to assessment data, but principals at high impact schools met with teachers to discuss student progress. One principal at a high impact school met individually with each teacher and had them write a plan on how to improve on weaknesses revealed in the data. Conversely, one average impact principal in the same study stated that she made copies of the data and placed them in faculty mailboxes with the expectations that they would discuss the data in their next departmental meeting.

In light of the existing research, this finding was surprising. This research would suggest that principals are more likely to meet with groups of teachers than they are to meet with teachers individually. Meeting with the teachers individually would allow the principal to develop a dialogue with the teachers about their results and what next steps might seem logical. 


\section{Discuss academic performance results with faculty to identify curricular}

strengths and weaknesses. This item of the PIMRS (1982) asked individual teachers,

"To what extent does your building principal discuss academic performance results with faculty to identify curricular strengths and weaknesses?" Analysis of Variance detected a statistically significant difference when comparing responses to this item $(\mathrm{F}=3.911 ; \mathrm{df}=2$; $\mathrm{p}<0.023)$. The mean response for this item across the three Performance Index groups was 3.80. Descriptive data to help examine this item can be found in Table 5.2.

Teachers in the medium Performance Index group responded that they perceived their principal to engage in this behavior "frequently" which would indicate that while principals in that group are meeting with faculty as a whole, they may not be meeting as much with individual teachers as noted previously. Bonferroni and Scheffe post-hoc comparisons showed the significant difference on this item to be based on differences between the means of the low and medium Performance Index groups.

Table 5.2

Discuss Performance Results with Faculty

\begin{tabular}{ccccc} 
& Low & Medium & High & Total \\
\cline { 2 - 5 } $\mathrm{N}$ & 88 & 68 & 43 & 199 \\
Mean & 3.61 & 4.04 & 3.81 & 3.80 \\
SD & 0.92 & 0.95 & 1.03 & 1.12 \\
\hline
\end{tabular}

Once again, the medium PI teachers perceived their principals to be more active in this behavior than the high PI teachers, although the difference was not statistically significant. 
The difference between the low and medium PI groups is supported in the principal leadership literature. Fullan (2008) cites the importance of the principal leading discussions with school staff about the progress of the school toward the school's goals. Marzano, Waters \& McNulty (2005) concluded from their meta-analysis that monitoring the effectiveness of the school's curricular, instructional and assessment practices are part of the behaviors associated with effective school leadership.

This item follows the pattern of the medium Performance Index teachers rating their principal more active in monitoring student progress than the high PI group. Once again, it is interesting to note that the medium PI teachers perceived their principals to engage in this behavior "frequently" while they rated principal activity in the first item close to "sometimes". This is an example of the likelihood that principals are meeting more with teachers in a group rather than individually.

\section{Use tests and other performance measures to assess progress toward school}

goals. This item of the PIMRS (1982) asked individual teachers, "To what extent does your building principal use tests and other performance measures to assess progress toward school goals?" Analysis of Variance detected a statistically significant difference when comparing responses to this item $(\mathrm{F}=7.030 ; \mathrm{df}=2 ; \mathrm{p}<0.002)$. The mean response for this item across the three Performance Index groups was 4.13 indicating that across the three groups, teachers perceived their principals to engage in this behavior "frequently". Descriptive data to help examine this item can be found in Table 5.3. Bonferroni and Scheffe post-hoc comparisons indicated the responses of the teachers in the low Performance Index group were significantly less than both the responses of the medium and high PI groups. 
Table 5.3

Use Tests to Assess Progress

\begin{tabular}{ccccc} 
& Low & Medium & High & Total \\
\cline { 2 - 5 } $\mathrm{N}$ & 88 & 68 & 43 & 199 \\
Mean & 3.86 & 4.34 & 4.33 & 4.13 \\
$\mathrm{SD}$ & 0.87 & 0.86 & 0.92 & .90 \\
\hline
\end{tabular}

Leithwood et al. (2004) found that the systematic use of student testing data for district planning was identified as a characteristic of academically effective school districts. Using tests and other performance measures is not only important in evaluating pupil, class and school levels of performance and progress (Southworth, 2002) but should also be used to identify and celebrate successes (Cotton, 2003).

This aspect of principals monitoring student progress fits in well with what building leaders are expected to do in the Ohio Improvement Process (OIP). The OIP is the planning framework that districts in school improvement status must utilize as part of Ohio's Differentiated Accountability Model. The medium and high PI groups had virtually identical ratings on this item with teachers from both categories perceiving that their principals were engaging in this type of behavior "frequently". This is encouraging data for those interested in what impact the Ohio Improvement Process is having on principal leadership.

Inform teachers of the school's performance results in written form. This item of the PIMRS (1982) asked individual teachers, "To what extent does your building principal inform teachers of the school's performance results in written form (e.g., in a memo or newsletter)?" Analysis of Variance detected a statistically significant difference 
when comparing responses to this item $(\mathrm{F}=3.335 ; \mathrm{df}=2 ; \mathrm{p}<0.007)$. The mean response for this item across the three Performance Index groups was 4.11. Descriptive data to help examine this item can be found in Table 5.4. Teachers in both the medium and high Performance Index groups responded that they perceived their principals to engage in this behavior "frequently". Bonferroni and Scheffe post-hoc comparisons showed there was a statistically significant difference between the means of the low and medium Performance Index groups.

Table 5.4

Inform Teachers of the School's Performance Results in Written Form

\begin{tabular}{ccccc} 
& Low & Medium & High & Total \\
\cline { 2 - 5 } $\mathrm{N}$ & 88 & 68 & 43 & 199 \\
Mean & 3.84 & 4.35 & 4.26 & 4.11 \\
$\mathrm{SD}$ & 1.04 & 0.96 & 1.11 & 1.05 \\
\hline
\end{tabular}

Principal-led, school wide examination of data has been found to be associated with a significant influence on student achievement (Robinson, 2007). The Education Trust (2005) also found that high impact administrators communicated test score information more formally than average impact administrators. Hallinger \& Murphy (1985) found that an important aspect of instructional leadership included school leaders presenting written reports of school assessment results in a timely fashion.

The researcher found significant difference between the low and medium PI groups on this item interesting. It points out the trend that the principals from the low Performance Index schools weren't really doing much in the way of monitoring student progress. Informing teachers in writing of the school's performance results is not a 
difficult, time intensive or particularly invasive thing to do. In other words, if you are not doing this as a building principal, what are you doing?

\section{Inform students of the school's academic progress.}

This item of the PIMRS (1982) asked individual teachers, "To what extent does your building principal inform students of the school's academic progress?" Analysis of Variance detected a statistically significant difference when comparing response to this item $(\mathrm{F}=6.700 ; \mathrm{df}=2 ; \mathrm{p}<0.002)$. The mean response for this item across the three Performance Index groups was 3.63 indicating that across the three groups, teachers perceived their principals to engage in this behavior "sometimes". Descriptive data to help examine this item can be found in Table 5.5. Bonferonni and Scheffe post-hoc comparisons indicated significant differences between the responses of teachers in the low Performance Index group and both the medium and high PI groups. The mean responses of the teachers in the high PI group were higher on this item than the responses of teachers in the medium PI group. This is the only item of the five PIMRS items where this was the case, although the difference was not statistically significant.

Table 5.5

Inform Students of the School's Academic Progress

\begin{tabular}{ccccc} 
& Low & Medium & High & Total \\
\cline { 2 - 5 } $\mathrm{N}$ & 87 & 68 & 43 & 198 \\
Mean & 3.31 & 3.84 & 3.96 & 3.63 \\
SD & 1.18 & 1.15 & .82 & 1.14 \\
\hline
\end{tabular}


This finding is not surprising as previous research has suggested that principals who maintain a student-centered focus are perceived by teachers and supervisors as the strongest instructional leaders (Hallinger \& Murphy, 1985). Also lending support in the literature is Hamilton et al. (2009). This work suggested that teaching secondary school students to use their own achievement data to monitor their progress can lead to increased student motivation.

This item represents an opportunity for future research. The trend for this item reflected the tendency for frequency of principal behavior on this item to increase as student achievement increased. As the only item, where the high Performance Index teachers rated their principals higher than the high PI teachers and with significant differences between the low group and both the medium and high PI groups, this item might be fertile ground for future investigation.

Teachers' perceptions of standardized testing. These eleven items were added to the PIMRS. Seven of these items investigated teacher attitudes towards student achievement tests and student achievement data. None of these items showed a statistically significant relationship across academic achievement levels.

Table 5.6

Means of Teachers' Perceptions of Standardized Testing

1. Results from student achievement data should drive our curriculum

2. Results from student achievement data should drive our teachers' instruction.

3. Student achievement data helps me do my job better.

\begin{tabular}{cccc} 
Low & Medium & High & Total \\
\hline 3.66 & 3.51 & 3.90 & 3.66
\end{tabular}

$\begin{array}{llll}3.77 & 3.61 & 3.98 & 3.76\end{array}$

$\begin{array}{llll}3.66 & 3.62 & 3.71 & 3.66\end{array}$


4. Preparing students for achievement testing can be a very useful learning activity.

$\begin{array}{llll}3.48 & 3.44 & 3.43 & 3.46\end{array}$

5. Standardized achievement tests get in the way of my work.

6. Results from achievement test scores help me plan instruction more effectively.

7. The Ohio Academic Standards define well what I believe students need to learn.

Teacher perceptions of the use of student achievement data. Results for the four items that addressed teacher perceptions of the use of student achievement data are presented in Table 5.7.

Table 5.7

Teachers' Perceptions of Achievement Data Use

1. Amount of time teachers spend reviewing student achievement data.

\begin{tabular}{cccc} 
Low & Medium & High & Total \\
\hline 1.94 & 2.02 & 2.02 & 1.98
\end{tabular}

2. Amount of time teachers spend $\begin{array}{lllll}\text { preparing students for standardized tests } & 2.32 & 2.49 & 2.45 & 2.41\end{array}$ such as the OGT.

3. Amount of time students spend taking standardized tests.

$\begin{array}{llll}2.34 & 2.49 & 2.55 & 2.44\end{array}$

4. Amount of time school $\begin{array}{lllll}\text { administrators spend reviewing student } & 2.12 & 2.18 & 2.20 & 2.16\end{array}$ achievement data.

Note. $1=$ Not enough time is spend on this activity. $2=$ Just the right amount of time is spent on this activity. $3=$ Too much time is spent on this activity. 
These results were a slightly surprising given some of the previous research on teacher attitudes towards standardized testing. In one example supporting this, Rapp (2002) found that $98 \%$ of his sample indicated that they either agreed or strongly agreed that students spend too much time preparing for tests. Rapp's study queried National Board Certified Teachers in Ohio. The findings in this study also contradict Rapp's finding that $91 \%$ of respondents either agreed or strongly agreed that high-stakes tests do not support developmentally appropriate practices for students (Rapp, 2002). A similar question in this study was "Preparing students for achievement testing can be a very useful learning activity." The results of this study indicated very little variance across Performance Index groups with the mean across all groups 3.46 - midway between Neutral and Agree. Perhaps it would be interesting to replicate Rapp's research now that No Child Left Behind is about a decade in. Maybe some of the anti-assessment perceptions have mellowed over the years.

\section{Implications}

Several patterns emerged from the data that should be of great interest to those interested in improving student outcomes by increasing the effectiveness of principal leadership. First, all three groups rated their principals lowest in the area of meeting individually with teachers to discuss student progress. While the results of this study did not indicate that this behavior was associated with higher student achievement, it is a practice that is supported in the literature and makes intuitive sense to practitioners. This practice would obviously take more time than to meet with staff in one setting which might explain why this item was rated so low across the three groups. 
Another pattern was teachers in the medium PI group perceived their principals to be engaging in four of the five behaviors more frequently than the high PI principals with "informing students of the school's academic progress" the lone exception. While that is interesting, the reader must consider that there were no significant differences between the medium and high Performance Index groups so statistically speaking they were the same. In searching for an explanation of why the low PI group would differ statistically from the medium but not the medium from the high, the researcher looked at Good to Great, the work of Jim Collins (2001) that sought to explain why some companies make that leap and others don't. Collins identified six fundamental concepts that his research identified as reasons why some companies went from "good to great". Of the six fundamental concepts, Confronting the Brutal Facts would be the one, above the remaining five, that might reflect the medium higher than the high phenomenon.

Perhaps the similarity between the medium and the high PI groups is the ability and/or willingness, or lack thereof, to confront the brutal facts. Collins labeled this, The Stockdale Paradox, which refers to having faith that you will prevail in the end, while at the same time, having the ability to confront the most brutal facts of your current reality. The explanation for why the medium PI group did not differ from the high PI group is that the medium group may have lacked the willingness or ability to confront their current reality with brutal honesty while the teachers in the high PI group felt more comfortable in realistically assessing the current reality of their principals' monitoring student progress behavior.

The researcher encountered this phenomenon as a school improvement consultant for the Region 12 State Support Team. District Leadership Teams from higher 
performing districts were likely to be more rigorous in their self-assessment of effective practices than District Leadership Teams from lower performing districts.

Having the willingness and/or ability to "confront the brutal facts" has local, state and national policy implications. Collins (2001) provides the following guidelines that would serve national, state and local policy makers well in helping to create a culture where people have the opportunity to be heard and for the truth to be heard:

1. Lead with questions not answers;

2. Engage in dialogue and debate, not coercion;

3. Conduct autopsies, without blame; and

4. Build "red flag" mechanisms.

At the local level, principals, superintendents and school boards must engage teachers and other stakeholders in intense dialogue in order to gain understanding. Only when leaders have the proper understanding can they ask the questions that lead to the best possible solutions. The same can be said of leaders and policy makers at the state and national levels. Collins explains, "Leading from good to great does not mean coming up with the answers and then motivating everyone to follow your messianic vision." (Collins, 2011, pp. 75)

The willingness to conduct autopsies without blame will be crucial to any school or district attempting to create a culture where the current reality can be faced with brutal honesty. Perhaps the teachers participating in this study from the medium Performance Index group felt more defensive about their current reality than the teachers from the high Performance Index group and that influenced the ratings of their building principals. In other words, the high PI group knew they were getting good results so they were more 
willing to rate their principal more rigorously than the medium PI group. Collins' sums up the importance of his four his four basic practices for creating a culture where people are willing to confront the brutal honesty,

Indeed, we found no evidence that the good-to-great companies had more or better information than the comparison companies. None. Both sets of companies had virtually identical access to good information. The key, then, lies not in better information, but in turning information into information that cannot be ignored. (Collins, 2001, 79)

The main implication of this study is that results suggest a relationship does exist between teacher perceptions of principal's monitoring student progress and student achievement. In four of the five items, there was a statistically significant difference in teachers' perception of principals' monitoring student progress behavior between the low Performance Index group and the medium Performance Index group. The low PI group differed significantly from the high PI group in two of the five survey items. These results are important and can provide a guide to school districts and building leaders who are struggling with improving student achievement. A popular radio talk show host is famous for saying, "If you want to be rich, you have to do rich people stuff!" The results of this study seem to be delivering a similar message to principals of low Performance Index schools. This researcher is not attempting to imply causation, but it seems that if you want to be a high Performance Index school, then you have to do "high Performance Index stuff”. At least four of the five principal behaviors on this list might be a good start for a principal in charge of a low performing school. These items can be implemented tomorrow by any principal who chooses to do so and they cost no money or close to nothing to put into place. A principal could begin to immediately use tests and other 
performance measures to assess progress toward school goals. There is no shortage of that type of data in schools today and the only thing it would cost the principal is time.

This notion is supported by policy makers at the national and state levels. The federal Race to the Top Grants require participating districts to have in place Instructional Information Systems that will provide the kind of data that schools need to monitor the progress of all students. In the state of Ohio, evaluation systems are addressing the degree to which the principal creates systems where data is used to improve instruction. Clearly, the results of this study provide some direction for principals struggling to effectively use data to monitor the progress of all students and to make instructional decisions based on the results of that data.

\section{Additional Research}

One recommendation for future research would be to revise or replicate PIMRS (Hallinger, 1983) but replace the five descriptors (almost never; seldom; sometimes; frequently; and almost always) with quantifiable anchors with values determined by the participants. For example, researchers could interview participants in each of the Performance Index groups to see what their perception of "almost always is". This would allow researchers to see if there is a difference in the way people perceive these descriptors. In other words, does "almost always" mean the same thing for the low Performance Index group as it does for the medium and high groups? This data would provide insight into what these descriptors mean to each Performance Index level.

Another future question might be around the increasingly distributed nature of school leadership. In other words, is someone other than the principal doing these instructional leadership behaviors? Phillip Hallinger, the creator of the PIMRS, is 
working in this area and is calling for increased attention to this phenomenon of distributed leadership. This line of questioning would be appropriate in Ohio as the Ohio Improvement Process is a planning framework designed with the intention to help districts increase their capacity in distributed leadership.

\section{Recommendations}

This research and the supporting literature provide several important recommendations for those interested in building the capacity of the building principal as instructional leader. First, the results of this research support the notion that teacher perceptions of the instructional leadership, specifically monitoring student progress, are related to student achievement in a positive way. A great first step for a principal struggling with instructional leadership in the domain of monitoring student progress would do well to focus on enacting the five behaviors described in the Monitor Student Progress subscale of the PIMRS. This is not provide the panacea for all the challenges that a high school principal faces, but it does provide a tangible, actionable and inexpensive start to building capacity in instructional leadership.

Central office personnel could use these results to guide their high school principals in creating plans to improve their monitoring student progress behavior. Statewide systems of support could help principals build capacity in this area by working on the specific behaviors studied.

The second recommendation would be the need to create the culture where principal monitoring student progress is not seen by staff as a "gotcha" but as a way to build systems that allow teachers to do the best job they can possibly do with as much information as they can possess. How teachers spend time in schools defines what the 
culture values. To build a culture that values collaboration requires that they system provide protected time for that collaboration to occur. Principals must promote and participate in this collaboration using the behaviors in the Monitor Student Progress subscale as a guide.

In light of recommendations one and two, the third recommendation this researcher makes in light of the findings of this study is to use these five items as a starting point for a coaching model that could be implemented on a regional level. This could be used as the starting point for a framework of capacity-building in the principal leadership domain of monitoring student progress. It seems common sense that if principals engage in these types of monitoring student progress behaviors, they will improve as instructional leaders. There is also a danger in underestimating the complexity of building a high school principal's capacity to perform instructional leadership responsibilities. It may be simple, but it is not easy! This research can provide the start for a coaching model to help principals in high schools with a low Performance Index build their instructional leadership capacity - a strategy which previous research, and the research from this study suggest is associated with higher student achievement results. 


\section{References}

ACT. (2008). The forgotten middle: Ensuring that all students are on target for college and career readiness before high school. Iowa City, IA: Author

Anderson, J. (2006). An analysis of the relationship of high school principal's perceived instructional leadership management behaviors to school size and student achievement (Doctoral dissertation). Retrieved from Proquest Dissertations and Theses. (3240565)

Andrews, R. \& Soder, R. (1987). Principal leadership and student achievement. Educational Leadership, 44, 9-11.

Armstrong, J. \& Anthes, K. (2001). How data can help: Putting information to work to raise student achievement. American School Board Journal, 38-41.

Armstrong, J. (2002). What is an accountability model? Denver, CO: Educational Commission of the States. Available: http://www.ecs.org.

Avolio, B. \& Bass, B. (Eds.), (2002) Developing potential across a full range of leadership. Mahwah, NJ: Lawrence Erlbaum Associates.

Bernhardt, V.L. (2004). Using data to improve student learning in middle schools. Eye on Education: Larchmont, NY.

Blake, R.B. \& Mouton, J.S. (1964) The Managerial Grid. Huston: Gulf Publishing.

Collins, J. (2001). Good to great: Why some companies make the leap... and others don't. New York, NY: HarperBusiness.

Cotton, K. (2003). Principals and student achievement: What the research says. ASCD: Alexandria, VA.

Edmonds, R. (1979). Effective schools for the urban poor. Educational Leadership, 37 , 
$15-24$

Glasman, N. (1984). Student achievement and the school principal. Educational Evaluation and Policy Analysis, 6(3), 283-296.

Glass, G. (1976). Primary, secondary and meta-analysis of research. Educational Researcher, 5(10), 3-8.

Fiedler, F.E. (1967) A theory of leader effectiveness. New York: McGraw-Hill.

Hallinger, P.J. (1983) Assessing the Instructional Management Behavior of Principals (Doctoral Dissertation). Available from ProQuest Dissertations and Theses database. (UMI no. 8320806)

Hallinger, P. (2003). Leading educational change: Reflections on the practices of instructional and transformational leadership. Cambridge Journal of Education, 33(3), 329-346. doi: 10.1080/0305764032000122005

Hallinger, P. \& Heck, R. (1996). Reassessing the principal's role in school effectiveness: A review of empirical research, 1980-1995. Educational Administration Quarterly, 32(1), 5-44.

Hallinger, P. \& Heck, R. (1998). Exploring the principal's contribution to school effectiveness: 1980-1995. School Effectiveness and School Improvement, 9(2), $157-191$.

Hallinger, P. \& Murphy, J. (1985). Assessing the instructional management behaviors of principals. The Elementary School Journal. 86(2), 217-247.

Hallinger, P. \& Murphy, J. (1986). The social context of effective schools. American Journal of Education, 94(3), 328-355.

Hamilton, L., Halverson, R., Jackson, S., Mandich, E., Supovitz, J., \& Wayman, J. 
(2009). Using student achievement data to support instructional decision making (NCEE 2009-4067). Washington, DC: National Center for Education Evaluation and Regional Assistance, Institute of Education Sciences, U.S. Department of Education. Retrieved from http://ies.ed.gov/ncee/wwc/publications /practiceguides/.

Hattie, J.A.C. (2009). Visible learning. NY: Routledge.

Hersey, P. \& Blanchard, K.H. (1969). Management of organizational behavior: Utilizing human resources. Englewood Cliffs, NJ: Prentice-Hall.

House, R.J. (1996). Path-goal theory of leadership: Lessons, legacy, and a reformulated theory. Leadership Quarterly, 7(3), 323-352.

House, R.J. \& Aditya, R.N. (1997). The social scientific study of leadership: Quo vadis? Journal of Management, 23(3), 409-473.

House, R.J., Spangler, W.D. \& Woycke, J. (1991). Personality and charisma in the U.S. Presidency: A psychological theory of leader effectiveness. Administrative Science Quarterly, 36, 364-396.

Immegart, G.L. (1988). Leadership and leader behavior. In N. Boyar (Ed.), Handbook of research on educational administration (pp. 259-277). New York: Longman.

Kirkpatrick, S.A. \& Locke, E.A. (1991). Leadership: Do traits matter? The Executive, $5(2), 48-60$.

Lai, E.R. \& Walman, K. (2008). Test preparations: Examining teacher perceptions and practices. Educational Measurement: Issues and Practices. 27(2), 28-45.

Leithwood, K., Harris, A. \& Hopkins, D. (2008). Seven strong claims about successful school leadership. School Leadership \& Management, 28(1), 27-42. 
doi: $10.1080 / 13632430701800060$

Leithwood, K. \& Jantzi, D. (1999). Transformational school leadership effects: a replication. School Effectiveness and School Improvement, 10(4), 451-479.

Leithwood, K., Louis, K.S., Anderson, S. \& Wahlstrom, K. (2004). How leadership influences student learning. Retrieved from http://mt.educarchile.cl/ MT/jjbrunner/archives/libros/Leadership.pdf

Leithwood, K. \& Mascall, B. (2008). Collective leadership effects on student achievement. Educational Administration Quarterly, 44(4), 529-561.

Leithwood, K. \& Montgomery, D. (1982). The role of the elementary school principal in program improvement. Review of Educational Research, 52(3). 309-339.

Leithwood, K., Patten, S. \& Jantzi, D. (2010). Testing a conception of how school leadership influences student learning. Educational Administration Quarterly, 46(5), 671-706. doi: 10.1177/0013161X10377347

Lewin, K., Lippit, R. \& White, R.K. (1939). Patterns of aggressive behavior in experimentally created social climates. Journal of Social Psychology, 10, 271301.

Lezotte, L. (n.d.). Revolutionary and evolutionary: The effective schools movement. Retrieved from http://www.iegallery.com/en/ie8slice/Default.aspx.

Likert, R. (1967). The human organization: Its management and value. New York: McGraw-Hill.

Marks, H. \& Printy, S. (2003). Principal leadership and school performance: An integration of transformational and instructional leadership. Educational Administration Quarterly. 39(3), 370-397. doi: 10.1177/0013161x03253412 
Marsh, J.A., Pane, J.F., \& Hamilton, L.S. (2006). Making sense of data-driven decisionmaking in education: Evidence from recent $R A N D$ research (OP-170). Santa Monica, CA: RAND Corporation.

Marzano, R., Waters, T. \& McNulty, B. (2005). School leadership that works: From research to results. ASCD: Alexandria, VA.

Mason, S. (2002). Turning data into knowledge: Lessons from six Milwaukee public schools. Madison, WI: Wisconsin Center for Education Research.

Mertler, C.A. (2010). Teachers' perceptions of the influence of No Child Left Behind on Classroom Practices. Current Issues in Education. 13(3).

Moore, T. (2008). Validation study: A collection of evidence about the Ohio Graduation Tests (TR 2008-01). Retrieved from Ohio Department of Education, Ohio Documents - Assessment Resources website: http://www.ohiodocs.org /Technical\%20Docs/TR\%202008\% 20-\%201\%200GT\%20Validity\%20Study\% 202006.pdf

Mulvenon, S.W., Stegman, C.E. \& Ritter, G. (2005) Test anxiety: A multifaceted study on the perceptions of teachers, principals, counselors, students and parents. International Journal of Testing. 5(1), 37-61.

Ohio Department of Education. (2007). Performance Index. Retrieved from www.ode.state.oh.us\%2FGD\%2FDocumentManagement\%2FDocumentDown load.aspx\%3FDocumentID\%3D29878\&ei=ZM_kTdffKZTqgAfy1qjIBg\&usg=A FQjCNHTIt871GALcEFQ3KEsVMISHK1hgw\&sig2=elvWSknqOlpwPolvoNyS2 Q

Ohio Department of Education, Office of Assessment. (July, 2010). March 2010 Ohio 
Graduation Test statistical summary. Retrieved from http://www.ode.state.oh.us/ GD/Templates/Pages/ODE/ODEDetail.aspx ?page $=3 \&$ TopicRelationID=285\& ContentID $=9479 \&$ Content $=96366$

Ohio Leadership Advisory Council. (2008). Ohio’s Leadership Development Framework. Organ, D.W. (1996). Leadership: The great man theory revisited. Business Horizons, 1-4. Paige, R. (2002, July 24). Stronger accountability. [Key Policy Letters Signed by the Educational Secretary or Deputy Secretary] United States Department of Education. Retrieved at http://www2.ed.gov/policy/elsec/guid/secletter/ 020724.html.

Paris, S. (1992). Four perspectives on educational assessment. International Journal of Disability, Development, and Education. 39, 95-105.

Purkey, S. \& Smith, M. (1983). Effective schools: A review. The Elementary School Journal, 83(4), 426-452.

Rapp, D. (2002). National Board Certified Teachers in Ohio give state educational policy, classroom climate, and high-stakes testing a grade of F. Phi Delta Kappan. 84(3). Rising Above the Gathering Storm: Energizing and Employing America for a Brighter Economic Future. (2005). Retrieved May 23, 2011, from National Academy of Sciences: http://www.nap.edu/catalog.php?record_id=11463

Rising Above the Gathering Storm, Revisited. (2010). Retrieved May 23, 2011, from National Academy of Sciences: http://www.nap.edu/catalog/12999.html Robinson, V. (2007). School leadership and student outcomes: Identifying what works and why (ACEL Monograph Series No. 41). Victoria, Australia: University of Melbourne, Centre for Organizational Learning and Leadership. Available at 
http://www.educationcounts.govt.nz/_data/assets/pdf_file/0020/13727/Leadership _Oration.pdf.

Robinson, V., Lloyd, C. \& Rowe, K. (2008). The impact of leadership on student outcomes: An analysis of the differential effects of leadership types. Educational Administration Quarterly, 44(5), 635-674. doi: 10.1177/0013161x08321509

Schmoker, M. (2009). Measuring what matters. Educational Leadership, 66(4), 70-74.

Sheppard, L. (1991). Will national tests improve student learning? Phi Delta Kappan, 232-238.

Stiggins, R.J., Arter, J.A., Chappuis, J., \& Chappuis, S. (2006). Classroom assessment for student learning: Doing it right-using it well. ETS: Portland, OR.

Southworth, G. (2002). Instructional leadership in schools: reflections and empirical evidence. School Leadership \& Management, 22(1), 73-91. doi: $10.1080 / 13632430220143042$

Supovitz, J.A. \& Klein, V. (2003). Mapping a course for improved student learning: How innovative schools systematically use student performance data to guide improvement. Philadelphia, PA: University of Pennsylvania, Consortium for Policy Research in Education.

Tannenbaum, A.S. \& Schmitt, W.H. (1958). How to choose a leadership pattern. Harvard Business Review, 36, 95-101.

The Education Trust. (2005). Gaining traction, gaining ground: How some high schools accelerate learning for struggling students. Retrieved from http://www.edtrust.org /sites/edtrust.org/files/publications/files/ GainingTractionGainingGround.pdf 
Vroom, V.H. \& Yetton, P.W. (1973). Leadership and decision-making. Pittsburgh: University of Pittsburgh Press.

Wayman, J.C., Brewer, C., \& Stringfield, S. (2009). Leadership for effective data use. Paper presented at the annual meeting of the American Educational Research Association, San Diego, CA.

Wayman, J.C., Cho, V., \& Johnston, M.T. (2007). The data-informed district: A districtwide evaluation of data use in Natrona County School District. Austin, TX: The University of Texas.

Weber, G. (1971). Inner-City Children Can Be Taught to Read: Four Successful Schools. Occasional Paper No. 18. Washington, DC: Council for Basic Education. 


\section{Appendix A}

\section{High Schools in Ohio Region 12}

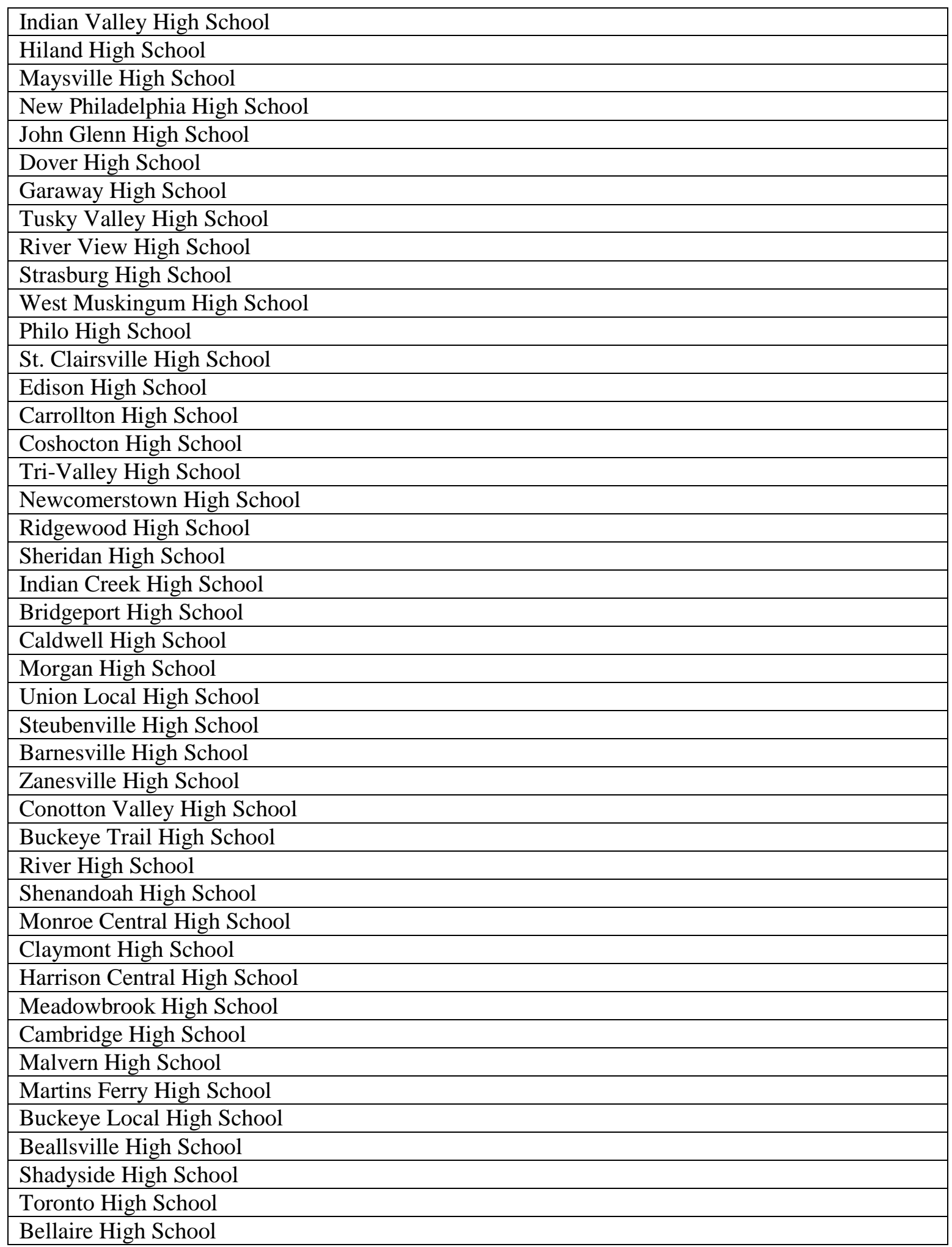




\section{Appendix B}

Letter of Permission to use the PIMRS

April 20, 2011

\section{T. C. Chappelear}

Dear Mr. Chappelear:

As copyright holder and publisher, you have my permission as publisher to use the Principal Instructional Management Rating Scale (PIMRS) in your research study. In using the scale, you may make unlimited copies of any of the three forms of the PIMRS.

Please note the following conditions of use:

1. This authorization extends only to the use of the PIMRS for research purposes, not for general school district use of the instrument for evaluation or staff development purposes;

2. The user must include a reliability analysis in the study if suitable quantitative data has been collected:

3. The user agrees to send a soft copy of the completed study to the publisher upon completion of the research.

4. The user agrees to send a soft copy of the data set to the publisher upon completion of the research.

Please be advised that a separate permission to publish letter will be sent after the publisher receives a soft copy of the completed study, the dataset, and I have confirmed that you included a reliability analysis.

Sincerely,

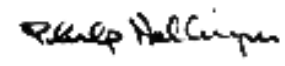

Professor Philip Hallinger

7250 Golf Pointe Way

Sarasota FL, 34243

Hallinger@gmail_com 


\title{
Appendix C
}

\author{
Superintendent Letter of Solicitation
}

Dear Superintendent,

My name is T.C. Chappelear and I am a school improvement consultant for the Region 12 State Support Team. I am also a doctoral student at West Virginia University, and currently beginning the research for my dissertation. The purpose of my study, which will take place in fall/winter 2011 , is to examine the potential relationship between perceived high school principals' monitoring student progress behavior and student academic achievement. I will be comparing the perceived monitoring student progress behavior of high school principals in Region 12.

I am requesting your participation because your high school(s) is/are part of the Region 12 service delivery area. The data that will be collected will be from teacher completed surveys from the high school(s) in your district. As this data is based on student performance from 2010-2011, one condition that must be met for participation in the study is that the current principal must have been the principal for at least the 2010-2011 school year.

Participation would simply consist of teachers completing a 5 minute on-line survey (the Principal Instructional Management Rating Scale) that assesses their perceptions of the principal's monitoring student progress behavior.

All information will remain completely confidential and will be coded so as to ensure anonymity. I will only access the information through a coded system and will not be able to match the data to your specific school district or school. The data will be stored in digital form on a USB memory key, which will be kept in a secure location at all times.

At the conclusion of my research, I will gladly provide you with a copy of the results, including the data summary and analysis.

If you would be interested in your district participating, please respond to this email stating your willingness to do so. I will then send you an official hard copy consent letter for your signature. I do need at least 21 schools throughout the region to participate, and will need at least $30 \%$ of your high school teachers to participate. Their data will be anonymous.

I hope you will consider being part of this study. I believe that it has the potential to help all of us learn more about our behaviors as principals and possible connections to student achievement.

Thank you for considering this invitation, and please do not hesitate to as me any questions. Response to this email does not obligate you to participate.

Sincerely,

T.C. Chappelear 


\title{
Appendix D
}

\author{
Formal Letter of Consent
}

\section{Dear Superintendent,}

Thank you for agreeing to allow the high school teachers at Barnesville High School to participate in my research study on perceived principal behavior in monitoring student progress and student academic achievement. This study is the basis of my dissertation, which I am completing in my pursuit of a doctoral degree in Educational Leadership Studies at West Virginia University.

Research indicates that the instructional leadership behaviors of the principal, including monitoring student progress are considered to be a critical aspect for the success of elementary schools. This study seeks to examine the relationship of principals monitoring student progress and student academic achievement at the high school level. This study will compare principals' monitoring student progress behavior through the administration of a survey instrument. The survey to be used (Principal Instructional Management Rating Scale) was developed by Dr. Philip Hallinger and has been utilized in over 100 studies around the world. Only the Monitoring Student Progress Subscale will be used for this study and should only take 5-10 minutes to complete.

The decision to participate is entirely yours and will not effect your current or future relations with West Virginia University. Once again, the survey is completely anonymous and the date coded. No identifying information will be reported. No information will be used in any published report that would make it possible to identify a subject.

I will store all data on a USB memory key that will be kept in a secure location when not in use. After five years, all raw data will be destroyed.

There are no risks associated with this study, and benefits may include the satisfaction that accompanies being involved in research that helps to identify specific leadership behaviors associated with increased student academic achievement.

Thank you once again. Please sign and date as indicated below and return in the enclosed selfaddressed and stamped envelope.

Sincerely,

\section{T.C. Chappelear}




\author{
Appendix E \\ Principal's Letter of Participation
}

Dear Colleague,

My name is T.C. Chappelear and I am a consultant for Ohio Valley Educational Service Center. I am also a doctoral student at West Virginia University, and currently beginning the research for my dissertation. The purpose of my study, which will take place in fall/winter 2011, is to examine the potential relationship between perceived high school principals' monitoring student progress behavior and student academic achievement. I will be comparing the monitoring student progress behavior of high school principals in Region 12.

Your superintendent has agreed to allow your high school to participate in this study. The data collected will be from teacher completed surveys from your high school. As this data is based on student performance from 2010-2011, one condition that must be met for participation in the study is that you have been the principal for at least the 2010-2011 school year.

Participation would include forwarding the link to a 5 minute on-line survey (The Principal Instructional Management Rating Scale - Monitoring Student Progress Subscale) that measures teacher perceptions of your monitoring student progress behavior. Their participation is completely voluntary, but would be greatly appreciated.

All information will remain completely confidential and will be coded so as to ensure anonymity. The data will be stored in a digital form on a USB memory key, which will be kept in a secure location at all times, and be destroyed five years after the completion of the study.

Thank you once again for your participation, and please do not hesitate to contact me if you have any questions or difficulties. Response to this email does not obligate you to participate.

Sincerely,

T.C. Chappelear 


\author{
Appendix F \\ Teacher Letter of Participation
}

Dear Colleague,

I have asked your principal to forward this email to you. My name is T.C. Chappelear and I am a school improvement consultant for the Region 12 State Support Team. I am also a doctoral student at West Virginia University, and currently beginning the research for my dissertation. The Principal Investigator for this study is Dr. Paul Chapman, Interim Associate Dean in the College of Human Resources at West Virginia University. His contact information is:

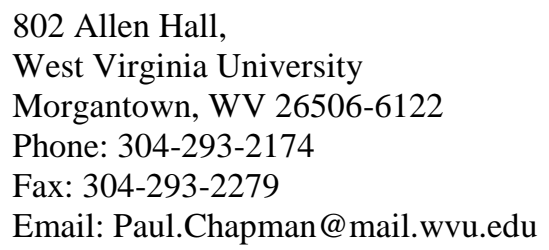

The purpose of my study, which will take place in fall/winter 2011, is to examine the potential relationship between perceived high school principals' monitoring student progress behavior and student academic achievement. I will be comparing the monitoring student progress behavior of high school principals in Region 12.

I am requesting your participation because your school, (name of school), is part of the Region 12 Statewide System of Support service delivery area. The data collected will be from teacher completed surveys from the high schools in Region 12. As this data is based on perceptions of your principal, one condition that must be met for participation in the study is that you worked with the current principal for at least the 2010-2011 school year.

Participation will include the completion of a 5 minute on-line survey (The Principal Instructional Management Rating Scale - Monitoring Student Progress Subscale) that assesses your perceptions of the principal's monitoring student progress behavior. Your participation is completely voluntary, but would be greatly appreciated.

West Virginia University's Institutional Review Board (IRB) has acknowledgement of this study on file. All information will remain completely confidential and will be coded so as to ensure anonymity. The data will be stored in a digital form on a USB memory key, which will be kept in a secure location at all times, and be destroyed five years after the completion of the study.

If you are willing to participate, please proceed with taking the survey by clicking on the following link or copying the address into your browser window: 〈Insert Link〉. The survey will be available for completion until midnight on <Insert Date>.

All questions must be answered and you must click next to move to the next page. The "Done" button must be clicked at the conclusion of the survey to officially record your responses.

Thank you once again for your participation, and please do not hesitate to contact me if you have any questions or difficulties. Response to this email does not obligate you to participate.

Sincerely,

T.C. Chappelear 


\section{Appendix G}

\section{Principal Instructional Management Rating Scale Form A}

This questionnaire is designed to measure your perception of the monitoring student progress behavior of your building principal. There are no personal identifiers included in this survey and there is absolutely no way to associate your responses with the school in which you are employed. The IP and Email tracking options of SurveyMonkey have been disabled for this survey to ensure complete anonymity. Your responses will be collected and pooled into one of three categories which each contain multiple high schools. Thank you for your participation.

Part l: Please provide the following information about yourself. This information will, in no way, identify you or the school in which you work.

1. At the end of this current school year (2011-2012), how many years will you have worked with the current principal?

1

$2-4$

5-9

10-15

more than 15

2. At the end of this current school year (2011-2012), how many total years experience will you have had as a full-time teacher (at any school)?
O 1
2-4
5-9
10-15
more than 15 


\section{Appendix G}

\section{Principal Instructional Management Rating Scale Form A}

PART II: This questionnaire is designed to provide a profile of principal leadership in the domain of Monitoring Student Progress. It consists of 5 behavioral statements that describe principal job practices and behaviors. You are asked to consider each question in terms of your obsenvations of the principal's leadership over the 20102011 school year.

Read each statement carefully. Then choose the number that best fits the specific job behavior or practice of this principal during the $2010-2011$ school year. For the response to each statement, you will be presented with the following choices:

\section{ALMOST ALWAYS \\ FREQUENTLY \\ SOMETIMES \\ SELDOM \\ ALMOST NEVER}

In some cases, these responses may seem awkward; use your judgment in selecting the most appropriate response to such questions. You will be able to choose only one number per question. Try to answer every question. Thank you.

1. TO WHAT EXTENT DOES YOUR PRINCIPAL..

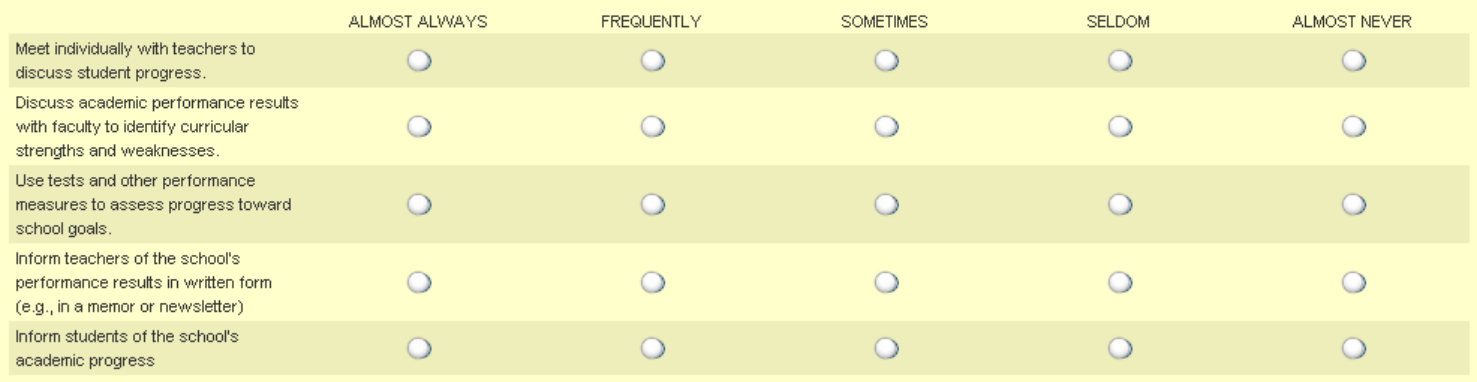

1. For each of the following items, please indicate your level of agreement by selecting the appropriate response.

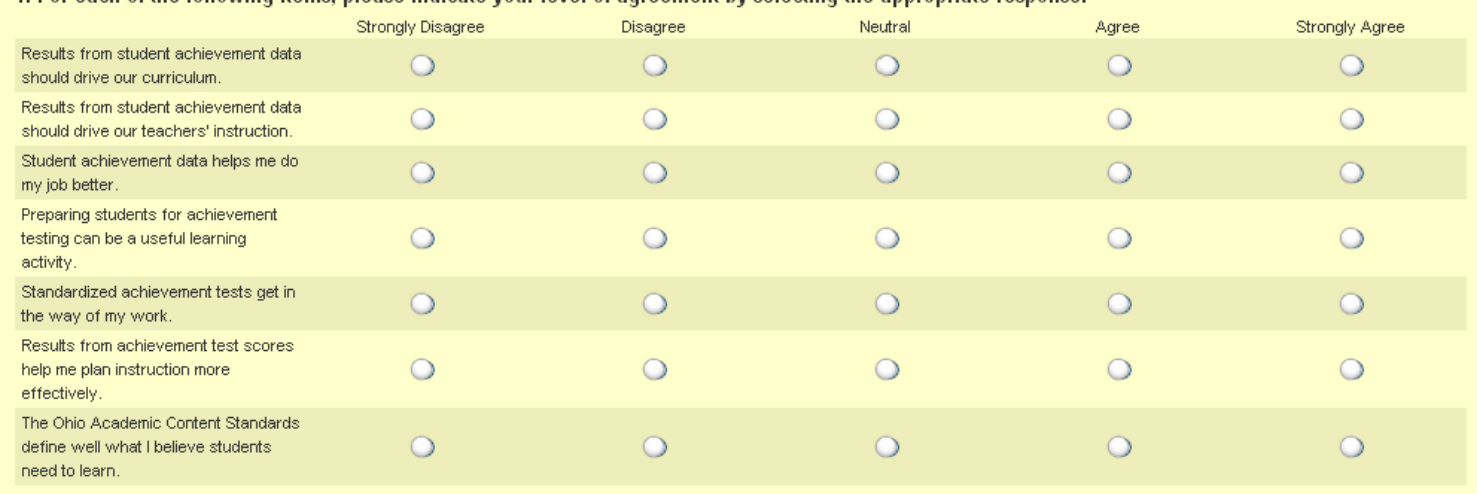

2. We are interested in measuring your perceptions of the use of student achievement data in public education. For each of the following, please indicate the appropriateness of time spent on that activity within your school district.

Amount of time teachers spend reviewing student achievement data. Amount of time teachers spen preparing students for standardized tests such as the OGT

Amount of time students spend taking standardized tests.

Amount of time school administrators spend reviewing student achievement
Just the right amount of time is spert on this activity.

\section{()}

O

(

O
Too much time is spent on this activity.

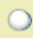

○

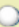

O

John

John H. $\mathrm{H}$. Virginia University Libraries, ou=Acquisitions Departmen email=John.Hagen@mail.wvu.e $\mathrm{du}, \mathrm{c}=\mathrm{US}$ 